\title{
Infectious Waste Management Strategy during COVID-19 Pandemic in Africa: an Integrated Decision-Making Framework for Selecting Sustainable Technologies
}

\author{
Amine Belhadi $\mathbb{D}^{1} \cdot$ Sachin S. Kamble ${ }^{2} \cdot$ Syed Abdul Rehman $\mathrm{Khan}^{3} \cdot$ Fatima Ezahra Touriki $^{4} \cdot$ Dileep Kumar M. $^{5}$
}

Received: 20 June 2020 / Accepted: 5 October 2020 / Published online: 23 October 2020

(C) Springer Science+Business Media, LLC, part of Springer Nature 2020

\begin{abstract}
The emerging and underdeveloped countries in Africa face numerous difficulties managing infectious waste during the SARS-CoV-2 disease, known as the COVID-19 pandemic. Hence, the main aim of this paper is to help decision-makers in African countries to select the best available waste management strategy during the COVID-19 pandemic. The present research undertakes seamless assessment and prioritization of infectious solid waste (SW) and wastewater (WW) treatment technologies based on a criteria system involving four dimensions, i.e., environment-safety, technology, economics, and sociopolitics. A combined approach that integrates the results of life-cycle assessments and life-cycle costs (LCA-LCC), analytic hierarchy process (AHP), and VIKOR method in an interval-valued fuzzy (IVF) environment is proposed. The results reveal that combined incineration and chemical disinfection approach, and combined chlorination and ultraviolet irradiation are the most sustainable technologies for managing infectious SW and WW treatment in the present context. The proposed approach, alongside the findings of the study, constitutes a reference to devise urgent planning for contagious waste management in African countries as well as developing countries worldwide.
\end{abstract}

Keywords COVID-19 $\cdot$ Municipal waste management $\cdot$ Waste water $\cdot$ AHP-VIKOR $\cdot$ Interval-valued fuzzy $\cdot$ Solid waste

\section{Introduction}

The new SARS-CoV-2 disease (commonly known as COVID-19) has induced a historical impact in most countries. Since the beginning of the pandemic, the virus has distressed almost all countries causing infection to several million and claiming thousands of lives according to WHO (2020a, b). The governments worldwide have implemented several measures to mitigate the propagation of the virus,

$\triangle$ Amine Belhadi

Belhadi.amine@outlook.com

1 Cadi Ayyad University, Marrakech, Morocco

2 EDHEC Business School, Roubaix, France

3 School of Economics and Management, Tsinghua University, Beijing, China

4 ENSA-Safi, Cadi Ayyad University, Marrakech, Morocco

5 Gopal Narayan Singh University, Jamuhar, India including personal protective equipment, social distancing, and lockdown (Klemeš et al. 2020).

The transmission behavior of SARS-CoV-2 is creating significant challenges for services related to solid waste (SW) and wastewater (WW) management. Aerosols, plastics, oral/fecal, and inanimate surfaces (fomites) are identified as the transmission medium for the virus (Nghiem et al. 2020). The multiple modes of transmission emphasize implementing a safety management system to interrupt the potential propagation of COVID-19 through SW and WW. The international organizations such as the World Bank and WHO (2020a, b) are extensively stressing the use of proper waste management (WM) mechanisms to prevent the transmission of COVID-19. The discharge of municipal SW and WW without appropriate treatment increases the probability of public exposure to infection WHO (2020a, b). In the context of the present pandemic, there is a need to take precautionary measures to avoid the risks associated with public health and the environment. Therefore, proper treatment and disposal of the infectious SW and WW are of great significance. 
The selection of the most efficient infectious waste treatment technology is a challenging task and depends on various criteria such as environment, safety, politics, and economics. The availability of diverse WM technologies with different levels of performance on selected criteria makes the decision-making complex. Furthermore, the ambiguous, incomplete, and inconsistent information to make these decisions adds uncertainty in decision-making (Valente and Bueno 2019; Voudrias 2016). A reliable procedure to prioritize the WM treatment technologies will be of great utility for the decision-makers (Wang et al. 2018).

The challenges for emerging and underdeveloped nations in Africa are even more significant (Belhadi et al. 2020). The budget for WM in most African countries is less compared to the other nations, constraining the treatment facilities, and posing severe threats to public health (Idowu et al. 2019). The waste generation during the COVID-19 at the sanitary and environmental levels is gaining more interest in African countries. The municipal WM assumes significant importance in most emergency response projects announced by African countries to fight the COVID-19 pandemic. Although the researchers have extensively studied the different alternatives and technologies to manage general SW and WW disposal (Ayodele et al. 2018), specific studies concerning the treatment and disinfection of municipal SW and WW in the African countries in the context of the COVID-19 pandemic are nonexistent.

The evaluation of the SW and WW treatment is a multidimensional problem that should consider factors related to economy, safety, environment, society, technology, and politics. In recent times, multicriteria decision-making (MCDM) methods have gained high popularity in the WM area as a powerful tool to resolve decision problems involving multiple conflicting criteria. Approaches such as analytic hierarchy process (AHP), VlseKriterijumska Optimizcija I Kaompromisno Resenje (VIKOR), technique for order of preference by similarity to ideal solution (TOPSIS), and preference ranking organization method for enrichment of evaluations (PROMETHEE) have been used extensively in solving WM related problems. Several studies have combined fuzzy and rough sets theory with the MCDM techniques to overcome the problem of vagueness and imprecision of human thoughts (Wang et al. 2019; Kharat et al. 2019).

The context of COVID-19 is posing an enormous challenge in data collection leading to an increase of uncertainty and complexity related to WM decisions. This lack of information in defining the membership function may involve some hesitation in membership degrees of fuzzy sets. The decision-maker might not be fully confident about the preferences, resulting in some amount of uncertainty associated with their decisions. Therefore, the traditional fuzzy set theory will not be useful to describe the opinions of the decision-makers (Wang et al. 2018). Consequently, we propose to use the interval-valued fuzzy (IVF) sets to address the complexity of WM models in the context of COVID-19 and overcome the issues of vagueness (lack of sharp class of boundaries in human judgment and preference) and lack of information (Gupta et al. 2018).

With the above background, the present study seeks the answers for the following research questions (RQs).

RQ 1: How could WM alternatives be precisely prioritized under the high vagueness generated by the context of COVID-19?

RQ 2: What are the best alternatives for underdeveloped countries to manage infectious SW and WW in the COVID19 pandemic context?

In seeking the answers to the above RQs considering the criticality of the infectious municipal WM generated during the COVID-19 pandemic, this paper contributes to the development of a WM strategy during the COVID-19 pandemic by proposing a combined life-cycle assessment (LCA), life-cycle cost (LCC) analysis, and AHP-VIKOR method to select a WM treatment technology under the effect of IVF environment. The proposed MCDM approach deals with high uncertainty related to WM data and seeks to develop an integrated management program of infectious SW and WW by incorporating various factors. The study makes the following significant contributions:

(1) The use of IVF set theory to cope with the ambiguity and vagueness generated by the uncertain context of COVID-19 can alter the decision-making process.

(2) The use of LCA-LCC for evaluating quantitative criteria based on actual data collected from the African context.

(3) The combination of qualitative (secondary data) and quantitative (expert interviews) data to select the best alternative for SW and WW treatment.

(4) The proposition of an integrated approach for managing SW and WW during and after the COVID-19 pandemic.

The study was conducted based on data collected from selected companies in Morocco, Africa. A fuzzy interval multiattribute decision-making technique was used to address uncertainty in decision-making during the ranking of alternatives. While AHP was used to determine the critical weighting factors, VIKOR was employed to screen and rank choices using quantitative insights from LCA and qualitative judgment of experts.

The rest of this article is organized as follows. Background Literature section presents the background literature explaining the different challenges related to WM during the COVID-19 pandemic and the most used technologies 
for infectious WM. Materials and Methods section discusses the research methodology adopted in this study. The findings of the African case study are discussed in section An Empirical Study on Infectious WM in Africa. The outcome and implications of the study are discussed in section Discussion and Implications. Conclusion section presents the conclusions, limitations, and future scope of the study.

\section{Background Literature}

\section{Challenges of WM during COVID-19 Pandemic}

The continuous propagation of the COVID-19 pandemic entails increased impacts and challenges upon human health, economy, and global environment. In particular, the current COVID-19 pandemic outbreak raises various questions on the municipal waste handling and treatment practices related to the health and safety of workers and waste treatment facilities (Saadat et al. 2020).

More specifically, two significant challenges are identified. The first challenge is related to the sharp increase in SW produced by either healthcare facilities or households. For instance, in China, the generation of solid and medical waste in Hubei Province has increased by $370 \%$ during the pandemic, despite the notable decrease of $30 \%$ of the total volume of municipal SW, according to the State Council's Joint Prevention and Control Mechanism. Furthermore, Wuhan has shown an unprecedented increase in plastic waste generation in households by $500 \%$ from early January to late March 2020 (Tang 2020). The rationale behind this situation is that plastic-based materials present tremendous utility in dealing with the various mitigation measures implemented worldwide. For instance, scientists and customers consider single-use plastics a safe solution to manage the virus. This results in increased utilization and release of plastic products even for nonmedical purposes. Klemeš et al. (2020) argued that the conventional municipal treatment systems for handling and disposal of regular waste under normal conditions are not suitable for use in abnormal situations.

The likelihood of generating biomedical waste at the residential colonies and the healthcare centers is high during the COVID-19 outbreak. Household waste includes infected gloves, masks, and other protective equipment. The selfisolation and home quarantine of the patients due to the limited capacity of hospitals increases the possibility of infectious municipal SW generation at personal locations. To mitigate this challenge of a widespread generation of medical waste Klemeš et al. (2020) suggest a structural change in the existing WM procedures that include sorting, collection, treatment, and disposal, adhering to the current safety protocols for the waste collection workers. Despite the recent announcements on the safety precaution measures in handling infectious waste (WHO 2020a, b), the extensive generation of plastic and mixed waste presents logistical challenges, putting the economic and environmental concerns on a low priority.

The second challenge is related to the pathogenic characteristic and viral transmissibility of WW during the COVID-19 pandemic. The pathogenicity of WW can be illustrated through two perspectives. First, studies have confirmed the transmission potential of SARS-CoV-2 through untreated municipal WW (Mallapaty 2020; Ahmed et al. 2020). Second, previous studies during the SARS-CoV-1 epidemic in 2003 had found WW aerosols as a "high potential" way of virus transmission in contaminated cities (Jack 2006). Hence, WW during the COVID-19 pandemic could present a critical route of transmissibility of the virus. Besides, the increase in drugs and pharmaceutical product consumption during the COVID-19 outbreak would magnify the environmental impact and pathogenicity of WW. According to Gogoi et al. (2018), unmetabolized drugs and their metabolites are commonly considered as problematic trace contaminants as traditional WW treatment plants are unable to kill them entirely. The number of contaminants in WW would undoubtedly augment during the pandemic, and even more, if the drugs are consumed uncaringly (Yu et al. 2020; Chen et al. 2018). Therefore, specific stages of the WW treatment process, particularly in the upstream collection network, should be subject to disinfection and sterilization treatment to limit the propagation of COVID-19.

\section{Challenges of African WM during COVID-19 Pandemic}

Most African countries are suffering from an increasing share of the population living in cities that face a shortage of funds, inadequate WM facilities, and poor urban planning posing severe challenges to WM strategies. A WHO report states that only $24 \%$ of the rural population and $44 \%$ of the urban population in Africa have access to sanitation facilities. The Organization for Economic Co-operation and Development (OECD) claims that only 56\% of African cities dwellers have access to piped water, down from $67 \%$ in 2003 , and only $11 \%$ have a sewer connection OECD/GIZ (2019). Moreover, people in rural areas are reported to be twice less vulnerable than people in urban areas for access to clean and safe water WHO/UNICEF (2017).

Public and private operators such as local nongovernmental organizations (NGOs) working for improvements in the water, sanitation, and WM in Africa face difficulties because of financial, institutional, and technical problems (Badi et al. 2019; Friedrich and Trois 2016). 
Thus, most cities and towns across Africa lack the required resources and infrastructure to address the challenges of WM. Of particular concern are the issues related to the current COVID-19, i.e., dealing with the increasing volumes of wastes and preventing the human-to-human transmission of the SARS-CoV-2 through proper hygiene, sanitation, and efficient WM, which seem to be not fully provided in Africa (World Bank 2020).

The fast propagation of COVID-19 is likely to disproportionately influence the most destitute and vulnerable regions globally (Street et al. 2020). These countries require urgent and appropriate COVID-19 responses, including hygiene and WM within complex circumstances. Infectious SW and WW management have the potential to be a robust public health tool in Africa. However, alternatives to handling and disinfecting SW and WW need to be selected more reliably and reasonably. The solution should incorporate local constraints and sustainability objectives.

\section{Review of SW Management Treatments during the Pandemic}

The present section reviews the leading technologies of SW disinfection and treatment during the pandemic context.

\section{Incineration (INC)}

INC is one of the most efficient waste-to-energy conversion treatment processes for recycling the inorganic and plasticbased proportion of waste (Cobo et al. 2018). Klemeš et al. (2020) argued that INC $\left(90 \mathrm{~min}, 120^{\circ} \mathrm{C}\right)$ shows exceptional ability to treat hazardous waste. The relatively high INC (over $800^{\circ} \mathrm{C}$ ) results in an adequate decontamination cycle by killing most microorganisms. Hence, the tailings of this process can be safely manipulated following nonhazardous SW regulation (Hong et al. 2018). Besides, INC participates in air pollution through the generation of toxic air, such as chlorinated dibenzodioxins and dibenzofurans (Voudrias 2016).

\section{Chemical disinfection (CHD)}

CHD is often combined with mechanical crushing treatment (Hong et al. 2018). During the disinfection process, chemical disinfectants (chlorine dioxide, sodium hypochlorite, calcium hypochlorite, etc.) are mixed with the crushed, contaminated wastes and kept for sufficient time to inactivate infectious microorganisms. Chemical disinfectants are characterized by immediate effect, steady yield, and broad neutering spectrum ranging from microorganisms and viruses to bacteria spores (Voudrias 2016). Sodium hypochlorite, calcium hypochlorite, and chlorine dioxide are the widely used disinfectants because of their specific features such as being noncorrosive, odorless, tasteless, colorless, high solubility in water, and nonhazardous after treatment (Wang et al. 2020a, b). However, CHD can be considered only when the volume of infected wastes is small (Hong et al. 2018).

\section{Microwave/radio-wave disinfection (MCD)}

MCD is based on electromagnetic waves with a wavelength between $(2450 \pm 50)$ and $(915 \pm 25) \mathrm{MHz}$ (Veronesi et al. 2005). The main features of MCD are low energy consumption, fast action, higher heat yield, and little harmful effect on the environment with no toxic wastes or residues after disinfection (Veronesi et al. 2005). Moreover, the sterilization spectrum of bacteria is relatively broad, which can inactivate a wide range of microorganisms (Veronesi et al. 2005). Nonetheless, the process requires meticulous monitoring by advanced microwave instruments (Stolze and Kühling 2009).

\section{Steam disinfection/autoclave (STD)}

STD is a high heat-based technology efficient in disinfecting contaminated waste using saturated water steam, with a temperature exceeding $100{ }^{\circ} \mathrm{C}$ (Veronesi et al. 2005). Sanitary landfills are used to dispose of the treated waste at a specified temperature and duration. The water steam releases latent heat, destroying microorganisms due to coagulation and protein denaturation. The disinfection of potentially infectious wastes using steam does not release toxic gases.

\section{Reverse polymerization (RP)}

$\mathrm{RP}$ is microwave-assisted pyrolysis recognized with high lead for infectious metals and plastic waste (Undri et al. 2014). According to Voudrias (2016), RP systems could reach $80 \%$ of volume reduction with $6 \log 10$ pathogen inactivation. Moreover, sterilized residues from RP are generally stable and appropriate for sanitary landfilling after shredding (Undri et al. 2014). The main drawback of the method is the release of WW by $\mathrm{NaOH}$ used in the scrubber to monitor gaseous emissions. The cost of these technologies is the highest among the techniques considered acting as a primary barrier for acceptance Voudrias (2016).

\section{Review of WW Disinfection Treatments during the Pandemic}

In the literature, several specific disinfection treatments have been recommended to be included in the WW management chains. 


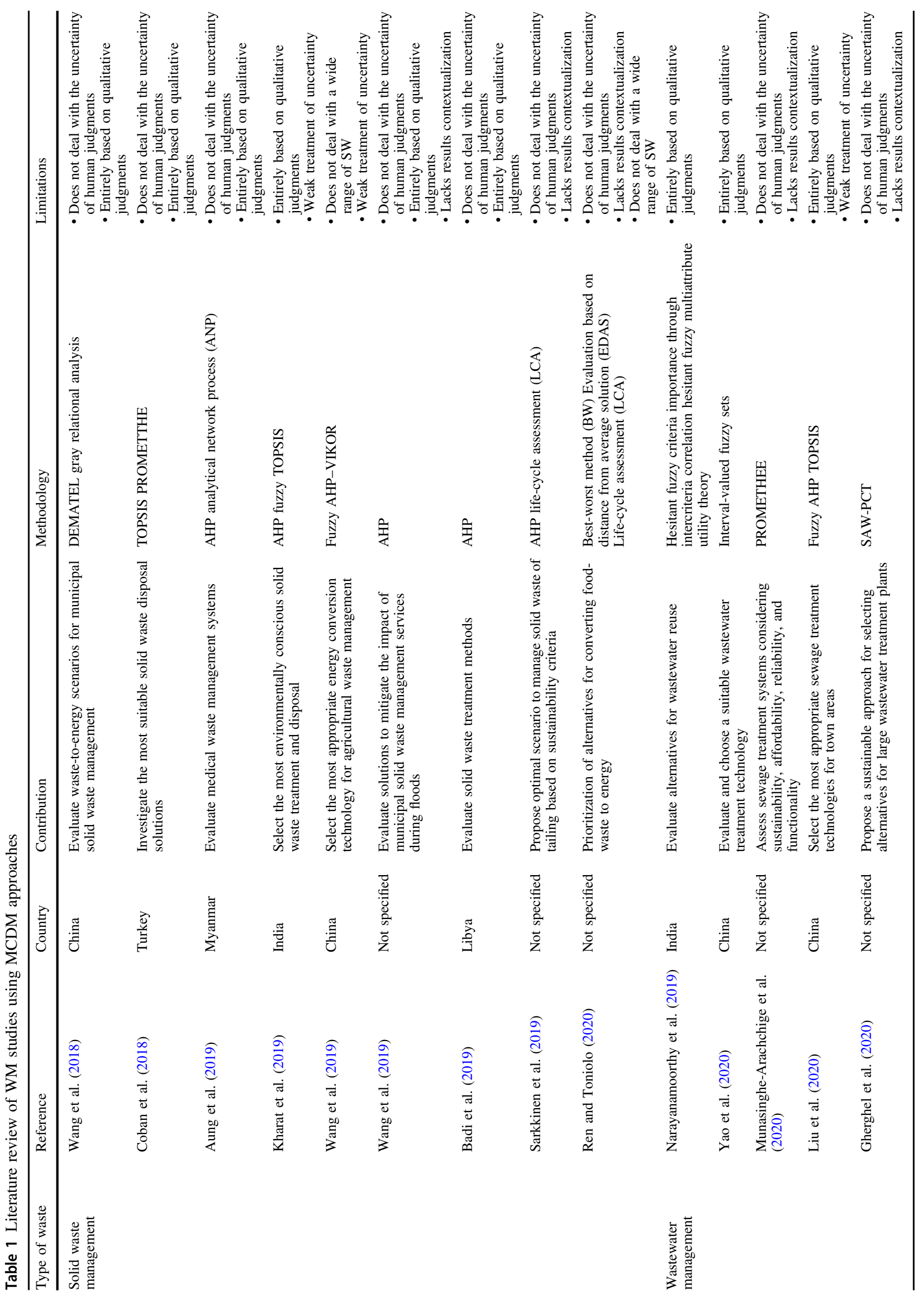




\section{Chlorination $(\mathrm{CHL})$}

CHL is the most commonly used WW disinfection treatment since the late I940s (Lazarova et al. 1999). CHL has a significant role in limiting waterborne infectious diseases worldwide; thereby, it is recommended by the WHO $(2020 \mathrm{a}, \mathrm{b})$. The generation of toxic residues, inadequate inactivation of the pores, increased costs because of dechlorination requirements, and high investments in safety equipment and scrubbing due to stringent safety regulations act as the main barriers for the use CHL technique (Hu et al. 2018; Lazarova et al. 1999).

\section{Ultraviolet (UV) irradiation (UVI)}

UVI is increasingly used as an alternative to CHL and found to be a highly efficient disinfectant for microorganisms (viruses and bacteria) (Lazarova et al. 1999). Currently, numerous installations around the world use open channels fitted with low-pressure mercury arc lamps to perform UVI disinfection (Zhang et al. 2019). The popularity of UV technology is mainly due to its low costs and the lack of toxic residues (Zhang et al. 2019). However, disinfection with UV is, at times, insubstantial due to insufficient penetration depth and risks on occupational health (Kühn et al. 2003).

\section{Ozonation (0ZO)}

$\mathrm{OZO}$ is based on ozone, which is a powerful oxidizing agent and useful in deactivating microorganisms (bacteria and viruses). Hence, OZO is widely utilized in water provision engineering and WW treatment (Wang et al. 2020a, b, Lazarova et al. 1999). However, ozone is a cystforming protozoan parasite, resistant to most other disinfectants (Lazarova et al. 1999). Although the involved process is complex, the dissolved molecular ozone is mainly useful for destroying a wide range of bacteria in drinking water (Lazarova et al. 1999). Moreover, several authors such as Im et al. (2018) and Von Gunten (2003) confirmed that ozone is highly useful to inactivate viruses.

\section{Ultrafiltration (UF)}

UF is based on a physical barrier concept to remove colloids and more abundant molecular weight organics. UF pilot tests performed with hydrophilic membranes (cut-off $0.01 \mu \mathrm{m}$ ) on different effluents showed complete removal of coliforms, Streptococci. Salmonella, Clostridium enteric viruses, and bacteriophages (Lazarova et al. 1999). Given that the diameter of SARS-CoV viruses is between 0.01 and
$0.012 \mu \mathrm{m}$ (Guy et al. 2001), UF can be an option to treat infected WW (Ahmed et al. 2020).

\section{Multi-Criteria Decision Making in Waste Management}

Studies on WM are mainly using MCDM techniques (i.e., AHP, VIKOR, TOPSIS, PROMETTHEE, etc.) as a solution method. Table 1 summarizes a critical review of recent studies on WM, including SW and WW, using MCDM approaches. Wang et al. (2018) used DEMATEL and grey relational analysis to investigate waste-to-energy scenarios in China. Besides, Coban et al. (2018) explored the SW disposal solutions through TOPSIS and PROMETTHE. Moreover, other studies have used AHP to evaluate SW, such as medical waste (Aung et al. 2019), floods' waste (Phonphoton and Pharino 2019), and municipal SW (Badi et al. 2019). Most of these studies lack the treatment of uncertainty due to human judgments. Kharat et al. (2019) and Wang et al. (2019) used a fuzzy set theory to treat uncertainty. However, the treatment of uncertainty was found to be relatively weak as the data used was mainly qualitative. Sarkkinen et al. (2019) and Ren and Toniolo (2020) used LCA to evaluate quantitative information but did not address uncertainty caused by qualitative judgments.

The existing literature on WW management using MCDM showed that Liu et al. (2020), Yao et al. (2020), and Narayanamoorthy et al. (2019) handled the issue of uncertainty using triangular, hesitant, and IVF sets while evaluating alternatives for WW treatment and reuse. However, they too considered qualitative judgment without any involvement of quantitative criteria. Gherghel et al. (2020) and Munasinghe-Arachchige et al. (2020) used some advanced MCDM techniques to rank and evaluate WW treatment plants such as PROMETTHE and simple additive weighting-paired comparison technique (SAW-PCT). Nevertheless, these studies were also based on human judgment without any treatment of uncertainty.

The review of recent literature on WM reveals several research gaps in the current literature. The methodologies used in the literature cannot be adopted in the current COVID-19 context, which is characterized by great uncertainty needing decision-making accuracy. These gaps can be summarized as follows:

(1) There are no studies in the recent literature to address SW and WW management jointly using the MCDM approach.

(2) The recent studies are suffering from absence or poor uncertainty treatment, as they do not deal with an ambiguous and uncertain situation such as COVID-19. 


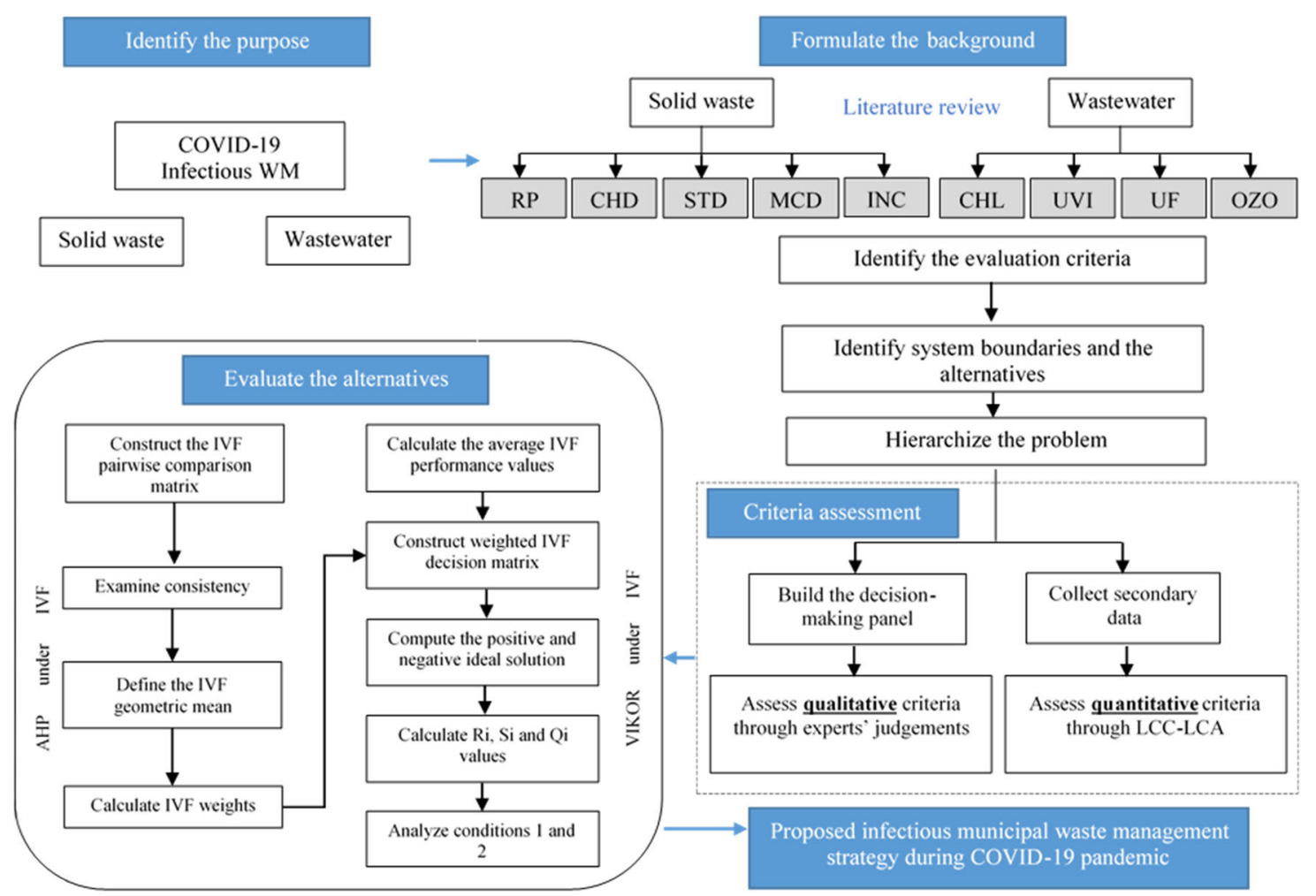

Fig. 1 The systematic procedure of the evaluation methodology

(3) Few studies rely on quantitative approaches to assess criteria to solve the problem.

To fill the gaps identified in the current literature, we propose an integrated approach combining LCA and LCC with AHP and VIKOR in an IVF environment.

\section{Materials and Methods}

The framework for the suggested methodology integrates LCA-LCC and MCDM to prioritize SW and WW treatment alternatives during the COVID-19 pandemic. The procedure is based on four elementary phases, as illustrated in Fig. 1.

(1) Identification of the purpose of the study.

(2) Development of the study background by identifying the system boundaries and a set of implementable alternatives derived from the SW and WW treatment technologies. The evaluation criteria are determined from the literature review. Finally, the problem hierarchy, including measures and alternatives, is established.

(3) Data collection and assessment of criteria using (qualitative) experts' judgments and (quantitative) LCA-LCC approach.
(4) Evaluation of the SW and WW treatment alternatives through IVF-AHP-VIKOR.

\section{Background of the Study}

The central aim of this study is to contribute to the global fight against the COVID-19 pandemic by helping decisionmakers to select the best choice among the technology alternatives of the treatment of the hazardous SW and WW generated during this pandemic period according to their safety and sustainability performances.

\section{Identification of the evaluation criteria}

The significant selection of the most suitable treatment technologies for the infectious SW and WW during the COVID-19 pandemic is a complex MCDM problem that implies consideration of multiple numbers of alternatives and evaluation criteria (Wang et al. 2020a, b; Cobo et al. 2018; Chen et al. 2006). The three dimensions of sustainability, viz., economic performance, environmental issue, and social concern, represent the ground of the selection criteria of the problem under study (Wang et al. 2019; Ren and Lützen 2015). Furthermore, the specific features of the COVID-19 pandemic require incorporating safety, 


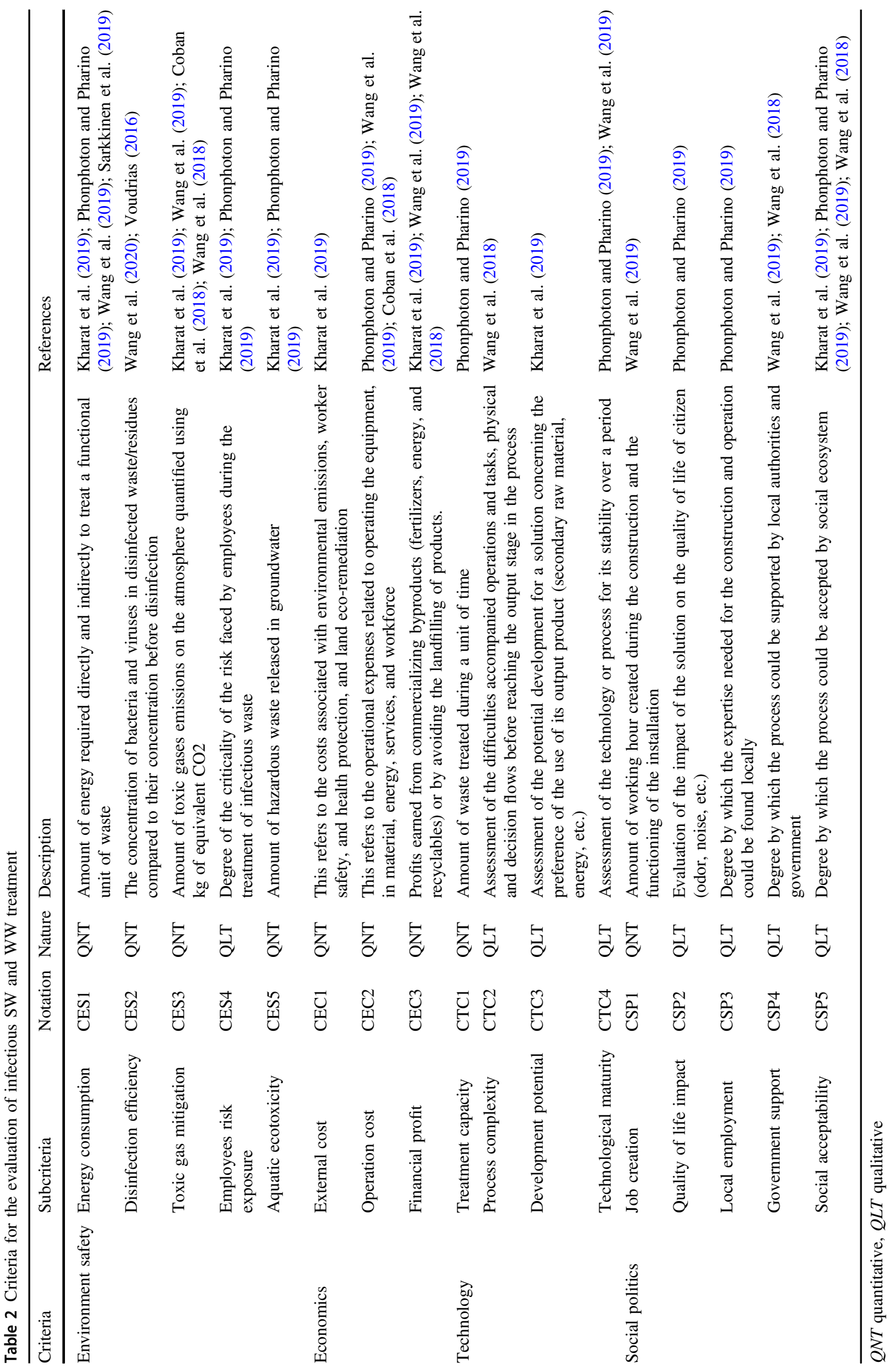


technology, and political considerations as these aspects influence the three pillars of sustainability. Table 2 depicts the descriptions of the subcriteria under the considered criteria. We assume that all of the evaluation criteria are independent, suggesting the absence of any interaction and interdependence among them.

\section{System boundaries and identification of alternatives}

The functional units for comparing the disposal of SW and WW are 1 tone and $1 \mathrm{~m}^{3}$, respectively. The Gate-to-gate approach was used to define the system boundaries that are a partial LCA, considering only the disposal process of municipal waste in the whole process of WM. The five reviewed SW treatments (i.e., RP, CHD, INC, STD, and MCD) were involved. The four reviewed WW treatments (i.e., CHL, OZO, UVI, and UF) were also considered. Building upon the existing literature and expert opinions, we have defined a set of infectious SW and WW treatment alternatives for our problem. Notably, the current studies in municipal WM proved the technical feasibility of different types of concrete choices (Istrate et al. 2020; Wang et al. 2018), with some of them already tested in the African context (Kabera et al. 2019; Ayodele et al. 2018). Besides, in-depth communication with a panel of experts and executives in several WM companies in Africa has focused on the challenges of infectious WM in Africa. The findings of the communications supported us in establishing the five scenarios for SW and four for WW treatment for further analyses. The system boundaries for the different scenarios are presented in Fig. 2. As the waste collection and storage practices were common to each scenario, they were excluded from the study.

Regarding infectious SW treatment, INC is considered a singular technique in the first alternative (SW1) and RP in the second alternative (SW2). More combined approaches, including
INC with CHD, STD, and MCD, are considered in (SW3), (SW4), and (SW5), respectively. As for infectious WW treatment, CHL is integrated with UVI in the first alternative (WW1), while UVI is considered independently in (WW2). Besides, a combined approach, including UF with UVI, is considered in (WW3) whereas only UF is included in (WW4). Finally, the fifth alternative (WW5) consists of OZO only.

\section{The hierarchal structure for the selection problem}

The problem decision hierarchy is conceptualized to integrate the criteria identified earlier for the assessment of the alternatives. As shown in Fig. 3, the problem hierarchy consists of four levels. The goal of the problem is represented by the first level and involves the selection of the most appropriate treatment technology for infectious SW and WW during the COVID-19 pandemic. The second level includes the specification of the predefined criteria, such as environmental-safety, economic, technical, and social-political, which are involved for further assessment. The subcriteria for each measure are included in the third level. The fourth level specifies the treatment alternatives used to accomplish the purpose, after their evaluation using the criteria and subcriteria.

\section{Criteria Assessment using LCA-LCC}

LCA is a methodology grounded in the Life-cycle thinking concept for performance assessment of a product or process throughout its life span involving manufacturing, consumption, and end of life (Heidari et al. 2020; NabaviPelesaraei et al. 2017). LCA is mainly applied to assess environmental and indirect social impacts. Further, Zanghelini et al. (2018) stated that LCA is highly compatible with MCDM techniques by enabling quantitative assessment of environmental indicators rather than being limited to qualitative evaluations. Following the ISO 14040
Fig. 2 SW and WW treatment scenarios-system boundaries. $\mathrm{RP}$ reverse polymerization, CHD chemical disinfection, INC incineration, STD steam disinfection, MCD microwave disinfection, CHL chlorination, UVI ultraviolet irradiation, UF ultrafiltration, $\mathrm{OZO}$ ozonation

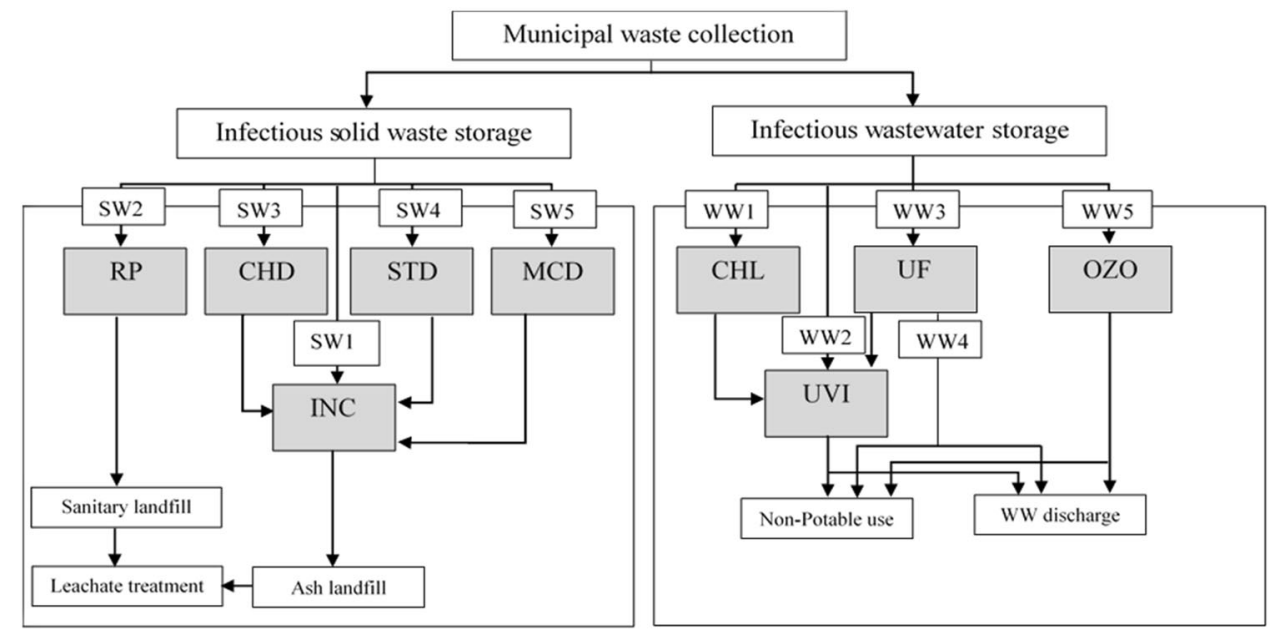




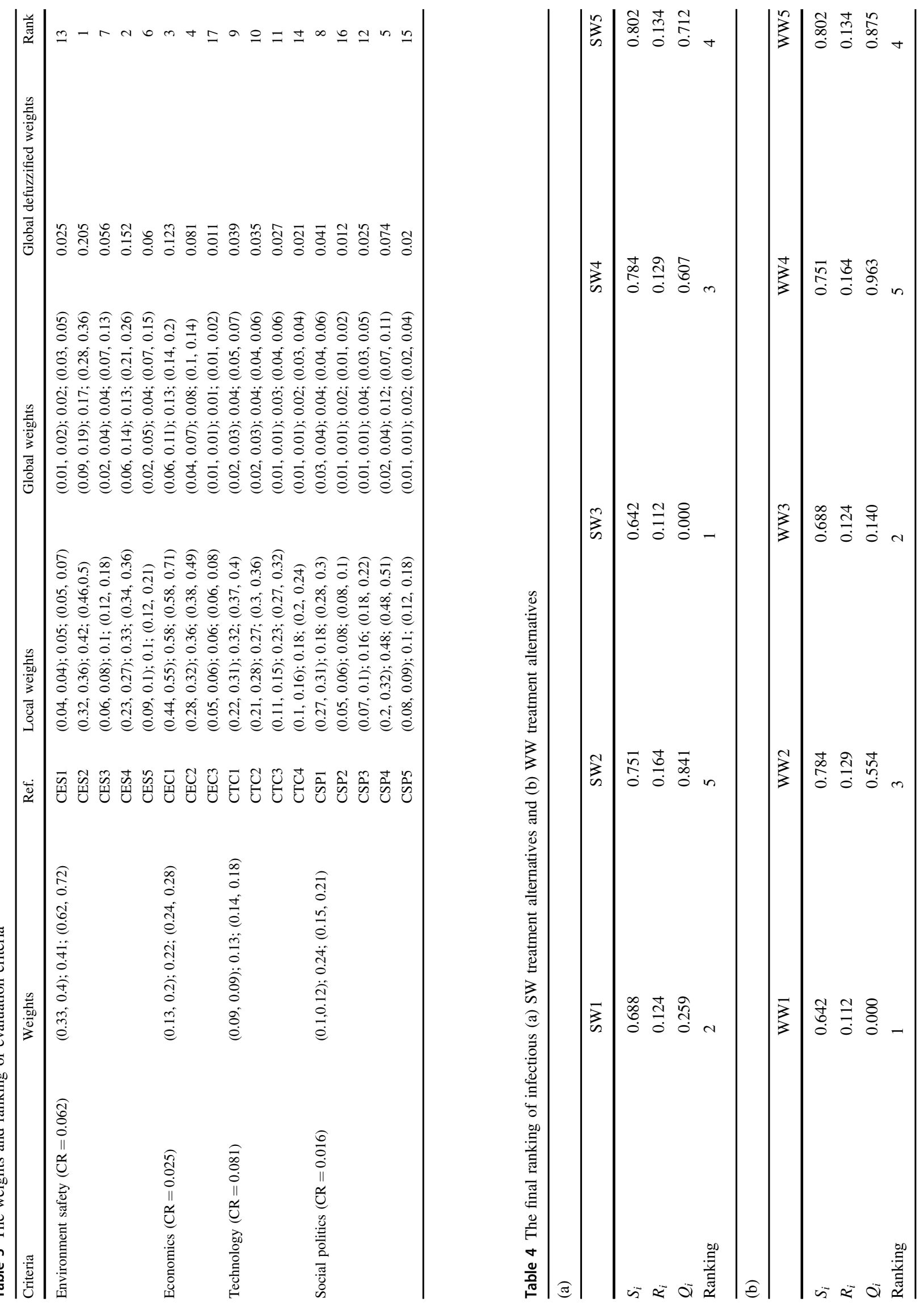


and ISO 14044, there are four main steps for LCA (Heidari et al. 2020; Zanghelini et al. 2018; Nabavi-Pelesaraei et al. 2017): (1) definition of scope and goal; (2) data collection and analysis; (3) assessment of environmental effects; and (4) interpretation of results.

LCC estimates the relevant cost throughout the life cycle of products or processes (Zanghelini et al. 2018). According to $\mathrm{Li}$ et al. (2019) LCC is an engineering economic analysis technique grounded on the principles of economic analysis to assess the long-term costs of different alternatives along a selected analysis period. Contrary to LCA, LCC does not have independent ISO standards. However, authors such as Li et al. (2019) mention two different ways to accomplish LCC, i.e., probabilistic and deterministic. While the deterministic way uses an accurate estimate for model input variables, the probabilistic way controls the uncertainty of variables using probability distributions. Usually, LCC variables are uncertain. The probabilistic way is thus highly appreciable.

\section{Evaluation of Alternatives using IVF-AHP-VIKOR}

\section{Interval-valued fuzzy AHP}

AHP under IVF environment is a commonly used MCDM approach to deal with both the intuitive and rational origins of uncertainty in determining the relative weights of the problem criteria (Saaty 1980, 1977). Therefore, fuzzy AHP is utilized to identify the relative importance of the $n$ criteria for the safety, politics, and sustainability evaluation of SW and WW treatment denoted as $\left\{\alpha_{1}, \alpha_{2}, \ldots, \alpha_{n}\right\}$ and the relative suitability of the $m$ alternative technologies regarding each criterion denoted as $\left\{\beta_{1}, \beta_{2}, \ldots, \beta_{m}\right\}$ using the opinions of $k$ decision-makers $\delta=\left\{\delta_{1}, \delta_{2}, \ldots, \delta_{k}\right\}$. Then, the output obtained from the fuzzy AHP is used in VIKOR method to prioritize the alternatives.

The IVF-AHP is conducted in three steps (Belhadi et al. 2017; Ren and Lützen 2015).

(1) Step 1: Construction of the fuzzy comparison matrices $(\tilde{C})$. The decision-making panel identifies the pairwise comparison matrix based on linguistic terms illustrated in Appendix I (Table 5). Triangular IVF numbers (TIVFNs) are employed to improve the ninepoint scale developed by Saaty (A scaling method for priorities in hierarchical structures 1977). The comparison matrix $\left(\widetilde{C}^{k}\right)$ can be presented as

$$
\widetilde{C}^{k}=\left[\widetilde{c}_{i j}^{k}\right]_{n \times n}=\left(\begin{array}{cccc}
\widetilde{1} & \widetilde{c}_{12}^{k} & \ldots & \widetilde{c}_{1 n}^{k} \\
\widetilde{c}_{21}^{k} & \widetilde{1} & \ldots & \widetilde{c}_{2 n}^{k} \\
\vdots & \vdots & \ddots & \vdots \\
\tilde{c}_{n 1}^{k} & \widetilde{c}_{n 2}^{k} & \ldots & \widetilde{1}
\end{array}\right)=\left(\begin{array}{cccc}
\widetilde{1} & \widetilde{c}_{12}^{k} & \ldots & \widetilde{c}_{1 n}^{k} \\
1 / \widetilde{c}_{12}^{k} & \widetilde{1} & \ldots & \widetilde{c}_{2 n}^{k} \\
\vdots & \vdots & \ddots & \vdots \\
1 / \widetilde{c}_{1 n}^{k} & 1 / \widetilde{c}_{2 n}^{k} & \ldots & \widetilde{1}
\end{array}\right),
$$

where $\widetilde{c}_{i j}^{k}=\left[\left(c_{1 i j}^{k}, c_{1 i j}^{\prime k}\right) ; c_{2 i j}^{k} ;\left(c_{3 i j}^{\prime k}, c_{3 i j}^{k}\right)\right]$ is a TIVFN representing the relative importance of the $i$ th criterion compared with the $j$ th criterion as obtained from decision-makers. The reciprocal of IVF number $\widetilde{c}_{i j}^{k}$ is $\frac{1}{c_{i j}^{k}}=\left[\left(\frac{1}{c_{3 i j}^{k}}, \frac{1}{c_{3 i j}^{k}}\right) ; \frac{1}{c_{2 i j}^{k}} ;\left(\frac{1}{c_{1 i j}^{k}}, \frac{1}{c_{1 i j}^{k}}\right)\right]$.

(2) Step 2: Examining the consistency of the fuzzy pairwise comparison $\widetilde{C}$ by evaluating the consistency of the defuzzified matrix $C$. The defuzzified $C$ is calculated using the center of area method, resulting in weights of each criterion.

$$
\text { Defuzzified }\left(\widetilde{c}_{i j}\right)=\frac{\left(c_{1 i j}+c_{1 i j}^{\prime}\right)+2 c_{2 i j}+\left(c_{3 i j}^{\prime}+c_{3 i j}\right)}{6} .
$$

In order to determine the consistency ratio (CR) of a matrix, Eq. (3) is first used to calculate the matrix consistency index CI.

$$
\mathrm{CI}=\frac{\lambda_{\max }-\mathrm{n}}{\mathrm{n}-1}
$$

where $\lambda_{\max }$ is the largest or principal Eigenvalue of the $C$ decision matrix of pairwise comparison as $A \omega=\lambda_{\max } \omega$. Then, the consistency ratio $(\mathrm{CR})$ is calculated by using the normalized random index, which depends on $n$ the matrix size, as

$\mathrm{CR}=\frac{\mathrm{CI}}{\mathrm{RI}}$

If $\mathrm{CR} \geq 0.1$, then the decision-makers must be consulted to revise their evaluations.

(3) Step 3: Determining the IVF weights of criteria of each decision-maker using the extended IVF geometric mean (Eq. (2)) developed by Csutora and Buckley (2001), as presented in Eqs. (2) and (3)

$$
\widetilde{r}_{j}=\left[\begin{array}{c}
\left.\left(\left(\prod_{k=1}^{n} c_{1 j k}\right)^{1 / n},\left(\widetilde{c}_{j 1} \otimes \widetilde{c}_{j 2} \ldots \otimes \widetilde{c}_{j n}\right)^{1 / n} c_{1 j k}^{\prime}\right)^{1 / n}\right) ;\left(\prod_{k=1}^{n} c_{2 j k}\right)^{1 / n} ; \\
\left(\left(\prod_{k=1}^{n} c_{3 j k}^{\prime}\right)^{1 / n},\left(\prod_{k=1}^{n} c_{3 j k}\right)^{1 / n}\right)
\end{array}\right],
$$

$$
\begin{gathered}
\widetilde{w}_{k}=\widetilde{r}_{k} \otimes\left(\widetilde{r}_{1} \oplus \widetilde{r}_{2} \oplus \cdots \oplus \widetilde{r}_{n}\right)^{-1} \\
\widetilde{w}_{k}=\left[\left(\frac{r_{1 k}}{\sum_{j=1}^{n} r_{3 j}}, \frac{r_{1 k}^{\prime}}{\sum_{j=1}^{n} r_{3 j}^{\prime}}\right) ; \frac{r_{2 k}}{\sum_{j=1}^{n} r_{2 j}} ;\left(\frac{r_{3 k}^{\prime}}{\sum_{j=1}^{n} r_{1 j}^{\prime}}, \frac{r_{3 k}}{\sum_{j=1}^{n} r_{1 j}}\right)\right],
\end{gathered}
$$


Fig. 3 The hierarchy of the problem

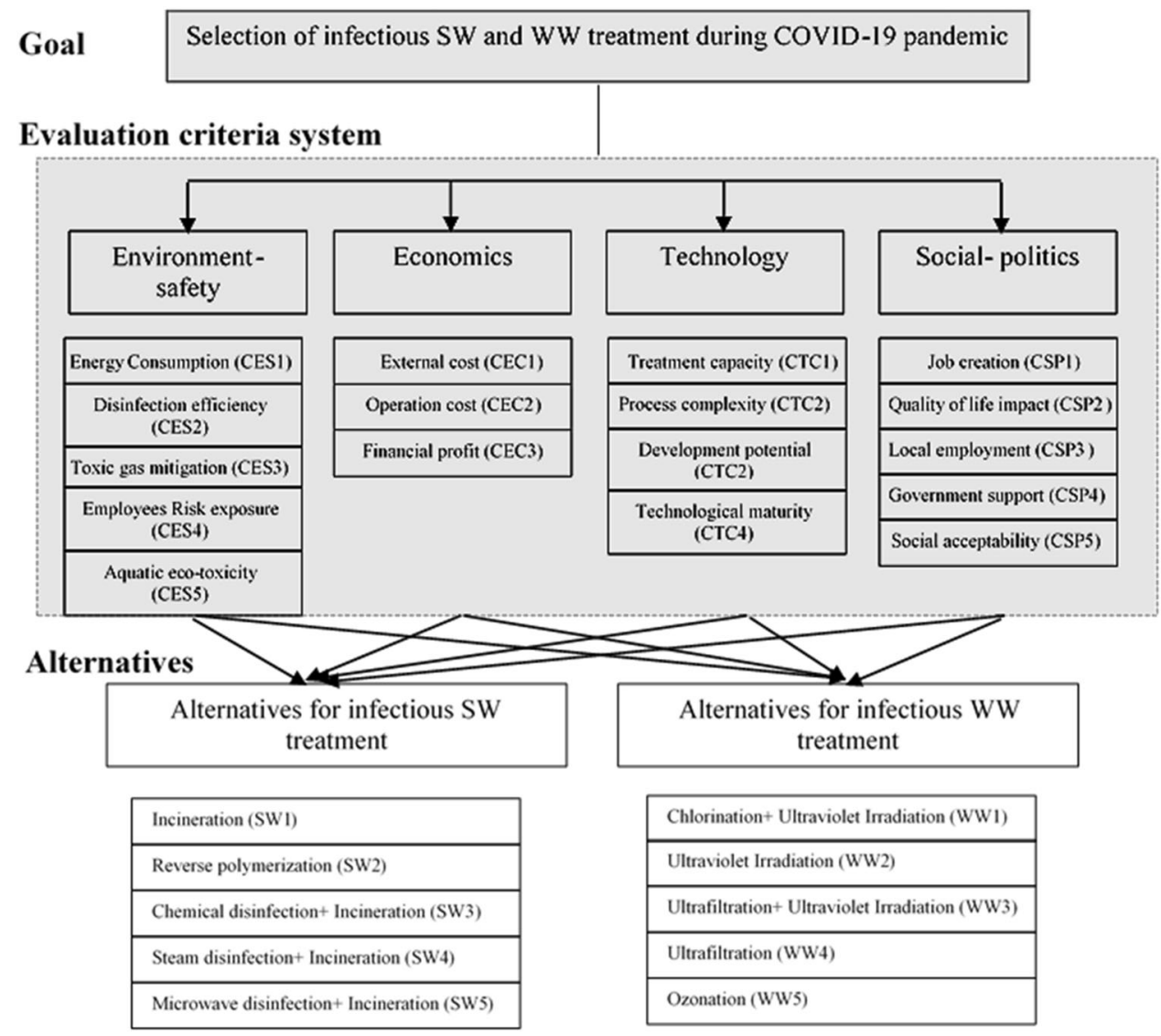

where $\widetilde{r}_{j}=\left[\left(r_{1 j}, r_{1 j}^{\prime}\right) ; r_{2 j} ;\left(r_{3 j}^{\prime}, r_{3 j}\right)\right]$ represents the geometric mean regarding the $j$ th decision-maker and stakeholder and $\widetilde{w}_{k}=\left[\left(w_{1 k}, w_{1 k}^{\prime}\right) ; w_{2 k} ;\left(w_{3 k}^{\prime}, w_{3 k}\right)\right]$ represents the relative weight of the $k$ th decision-maker.

\section{Interval-valued VIKOR}

VIKOR method is introduced as an MCDM approach relied on compromise solutions (Opricovic and Tzeng 2007; Opricovic 1998). This method aims at determining the compromise solution while prioritizing a set of alternatives in the existence of controversial criteria. The VIKOR method introduces the multihierarchical index, based on the particular measure of "closeness" to the "ideal" solution. In this study, the IVF-based extension of VIKOR is applied to carry out the selection of infectious SW and WW treatment selection during the COVID-19 pandemic. During the evaluation process, we consider a set of $m$ alternatives represented as $\left\{\beta_{1}, \beta_{2}, \ldots, \beta_{m}\right\}$ and a set of the $n$ pre-established assessment criteria $\left\{\alpha_{1}, \alpha_{2}, \ldots, \alpha n\right\}$. Accordingly, the steps of the IVF-based VIKOR are presented as
(1) Step 1: Constructing the aggregate fuzzy evaluation matrix for the ranking $\widetilde{F}=\left[\widetilde{f}_{i j}\right]_{m \times n}$ by using the linguistic scale illustrated in Appendix I (Table 5b) and the weighted IVF decision matrix $\widetilde{V}=\left[\widetilde{v}_{i j}\right]_{n \times m}$ based on IVF weights from IVF-AHP

$$
\begin{aligned}
& \begin{array}{llll}
\beta_{1} & \beta_{2} & \cdots & \beta_{m}
\end{array} \\
& \widetilde{F}=\left(\widetilde{f}_{i j}\right)_{n \times m}=\begin{array}{c}
\alpha_{1} \\
\alpha_{2} \\
\vdots \\
\alpha_{n}
\end{array}\left(\begin{array}{cccc}
\widetilde{f}_{11} & \widetilde{f}_{12} & \cdots & \widetilde{f}_{1 m} \\
\widetilde{f}_{21} & \widetilde{f}_{22} & \cdots & \widetilde{f}_{2 m} \\
\vdots & \vdots & \ddots & \vdots \\
\widetilde{f}_{n 1} & \widetilde{f}_{n 2} & \cdots & \widetilde{f}_{n m}
\end{array}\right),
\end{aligned}
$$

where $\widetilde{f}_{i j}=\frac{\widetilde{f}_{i j}^{1}+\widetilde{f}_{i j}^{2}+\cdots+\widetilde{f}_{i j}^{k}}{k}$ stands for the average rating of the $j$ th alternative $\beta_{j}$ with regard to $i$ th criterion $\alpha_{I}$ for the $k$ decision-makers

$\widetilde{v}_{i j}=\widetilde{w}_{i j} \otimes \widetilde{f}_{i j}=\left(\begin{array}{c}\left(w_{1 i j} \times f_{1 i j}\right),\left(w_{1 i j}^{\prime} \times f_{1 i j}^{\prime}\right) ; w_{2 i j} \times f_{2 i j} ; \\ \left(w_{3 i j}^{\prime} \times f_{3 i j}^{\prime}\right),\left(w_{3 i j} \times f_{3 i j}\right)\end{array}\right)$. 
(2) Step 3: Calculating the positive ideal solution $\left(p^{f^{*}}, p^{v^{*}}\right)$, and negative ideal solution $\left(N^{f-}\right)$ for upper and lower reference points of the IVFNs. There are two groups of criteria. The first group with the larger value, the optimal the alternatives, is called beneficial criteria, while the second is called cost criteria with the greater value, the nonoptimal the alternative

$$
\begin{aligned}
& p^{f *}=\left\{\tilde{f}_{1 j}^{*}, \tilde{f}_{2 j}^{*}, \ldots, \tilde{f}_{n j}^{*}\right\}=\left\{\max _{i} \tilde{f}_{i j}^{*} \mid i \in \text { Benefit }\right\} . \\
& p^{v *}=\left\{\tilde{v}_{1 j}^{*}, \tilde{v}_{2 j}^{*}, \ldots, \tilde{v}_{n j}^{*}\right\}=\left\{\max _{i} \tilde{v}_{i j}^{*} \mid i \in \text { Benefit }\right\} . \\
& N^{f-}=\left\{\tilde{f}_{1 j}^{*}, \tilde{f}_{2 j}^{*}, \ldots, \tilde{f}_{n j}^{*}\right\}=\left\{\max _{i} \tilde{f}_{i j}^{*} \mid i \in \text { Cost }\right\} .
\end{aligned}
$$

(3) Step 4: The computation of the values of the utility $\left(S_{i}\right)$ and the regret $\left(R_{i}\right)$ and the VIKOR index $\left(Q_{i}\right)$ based on the weights of criteria determined by IVFAHP using Eqs. (12)-(16), respectively

$$
\begin{aligned}
& S_{i}=\sum_{j=1}^{n} \frac{1}{2}\left(S_{i j}+S_{i j}^{\prime}\right), \quad \forall i=1,2, \ldots, m, \\
& R_{i}=\max _{j}\left(\frac{1}{2}\left(S_{i j}+S_{i j}^{\prime}\right)\right), \quad \forall i=1,2, \ldots, m,
\end{aligned}
$$

where

$$
S_{i j}=\sum_{i} \frac{\sqrt{\frac{1}{3} \sum_{k=1}^{3}\left[\left(v_{1 i}^{*}-v_{3 i}\right)^{2}+2\left(v_{2 i}^{*}-v_{2 i}\right)^{2}+\left(v_{3 i}^{*}-v_{1 i}\right)^{2}\right]}}{\sqrt{\frac{1}{3} \sum_{k=1}^{3}\left[\left(f_{1 i}^{*}-f_{3 i}^{-}\right)^{2}+2\left(f_{2 i}^{*}-f_{2 i}^{-}\right)^{2}+\left(f_{3 i}^{*}-f_{1 i}^{-}\right)^{2}\right]}}, \quad \forall i=1,2, \ldots, m
$$

$$
S_{i j}^{\prime}=\sum_{i} \frac{\sqrt{\frac{1}{3} \sum_{k=1}^{3}\left[\left(v_{1 i}^{\prime *}-v_{3 i}^{\prime}\right)^{2}+2\left(v_{2 i}^{\prime *}-v_{2 i}^{\prime}\right)^{2}+\left(v_{3 i}^{\prime *}-v_{1 i}^{\prime}\right)^{2}\right]}}{\sqrt{\frac{1}{3} \sum_{k=1}^{3}\left[\left(f_{1 i}^{\prime *}-f_{3 i}^{\prime}\right)^{2}+2\left(f_{2 i}^{\prime *}-f_{2 i}^{\prime}\right)^{2}+\left(f_{3 i}^{\prime \prime}-f_{1 i}^{\prime}\right)^{2}\right]}}, \quad \forall i=1,2, \ldots, m
$$

$$
Q_{i}=v \frac{\left(S_{i}-S^{*}\right)}{\left(S^{+}-S^{*}\right)}+(1-v) \frac{\left(R_{i}-R^{*}\right)}{\left(R^{+}-R^{*}\right)}, \quad \forall i=1,2, \ldots, m,
$$

where $\quad S^{*}=\min _{i} S_{i}, \quad S^{+}=\max _{i} S_{i}, \quad R^{*}=\min _{i} R_{i}$, $R^{+}=\max _{i} R_{i}$, and factor $\mathrm{v}$ is the weight of the decisionmaking strategy of "the maximum utility", which is comprised in the interval $[0,1]$ and is often considered as 0.5 .

(4) Step 5: The ranking of the alternatives by sorting the values of $S_{i}, R_{i}$, and $Q_{i}$ in ascending order. Note that the higher the values of $Q_{i}, S_{i}$, or $R_{i}$, the less superior the corresponding alternative will be. The alternative $\beta_{1}$ is suggested as a compromise solution that is ranked as the optimal by the measure $\mathrm{Q}\left(Q_{1}\right.$ is the smallest among $Q_{i}$ values) if the following two conditions can be fulfilled (Opricovic and Tzeng 2007):

Cond.1: Acceptable advantage: Alternative $\beta_{1}$ should satisfy $Q_{2}-Q_{1} \geq \frac{1}{m-1}$.

Cond.2: Acceptable stability in decision-making: Alternative $\beta_{2}$ should also be ranked as the optimal by $\mathrm{S}$ and $\mathrm{R}$.

If one of the conditions is not fulfilled, then a set of compromise solutions is proposed, which consists of

(1) Alternatives $\beta_{1}$ and $\beta_{2}$ if cond. 1 is fulfilled and cond.2 is not fulfilled (thus, both scenarios $\beta_{1}$ and $\beta_{2}$ are suggested as the optimal solutions).

(2) Alternatives, $\beta_{2}, \ldots, \beta_{m}$ if cond. 1 is not fulfilled (hence, a set of solutions $\beta_{1}, \beta_{2}, \ldots, \beta_{m}$ is suggested as the optimal choices); $\beta_{m}$ is identified by the equation $Q_{m}-Q_{1} \leq \frac{1}{m-1}$ for maximum $m$ (the positions of these alternatives are "in closeness").

\section{An Empirical Study on Infectious WM in Africa}

Municipal WM is a significant issue in most developing countries, especially in Africa. Yet, factors such as shortage of funds and increasing share of the population living in cities pose severe challenges to municipalities to provide
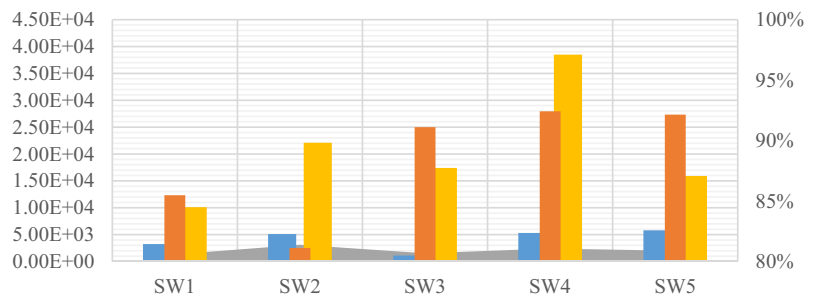

- Toxic gas release $(\mathrm{Kg} \mathrm{CO} 2 \mathrm{Eq})$ Energy consumption $(\mathrm{Kj})$

- Aquatic ecotoxicity (CTUe) Disinfection efficiency (\%)

(b)

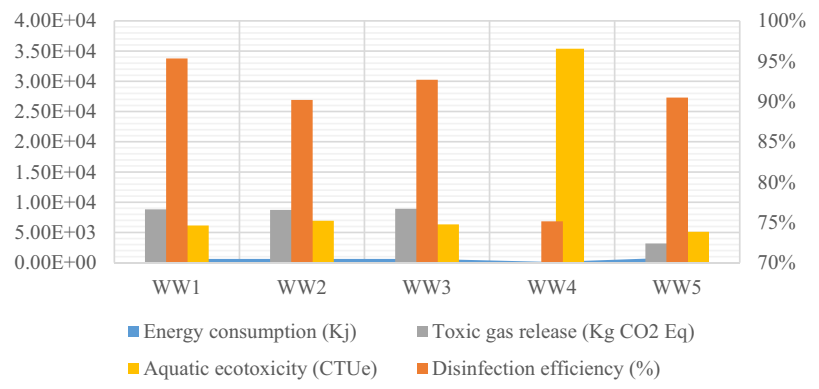

Fig. 4 The results of a solid waste treatment and $\mathbf{b}$ wastewater treatment alternatives under environmental criteria 

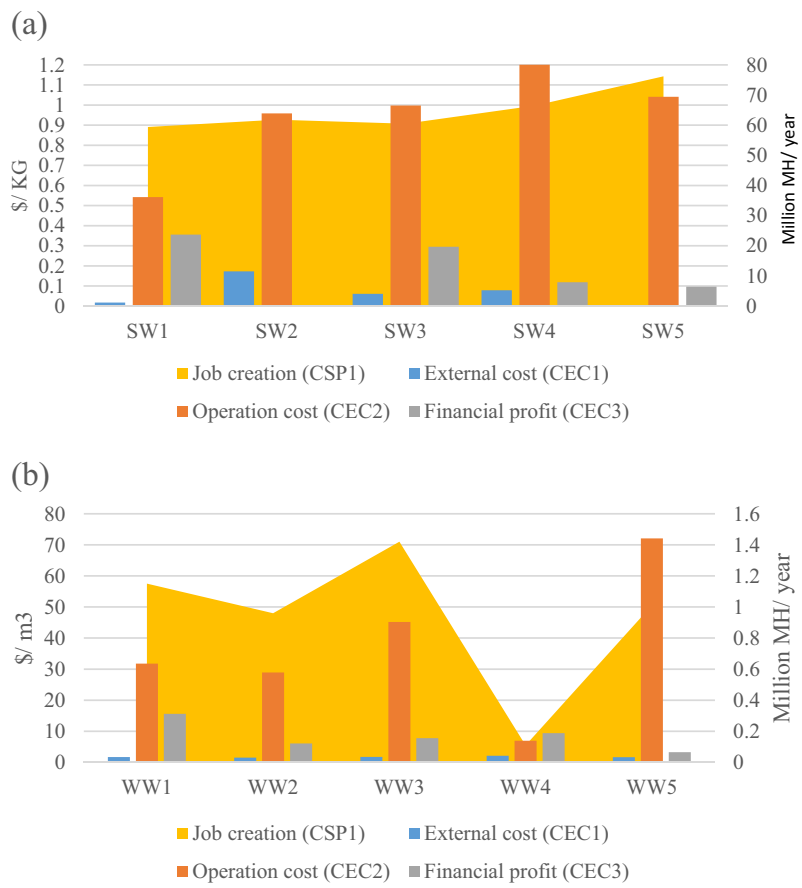

Fig. 5 The results of a solid waste treatment and $\mathbf{b}$ wastewater treatment alternatives under techno-economic criteria

efficient WM (Idowu et al. 2019; Ayodele et al. 2018; Nahman and Godfrey 2010) during the current COVID-19 pandemic. The World Bank is approving health emergency funds to assist several African countries in their COVID-19 emergency response projects, including an Infection Control and WM Plan for the proper management of contaminated SW and WW during the current COVID-19 pandemic (UNICEF 2020). Thus, selecting the appropriate treatment for infectious SW and WW would be of paramount usefulness for African countries.

\section{Data Acquisition and Assessment of Criteria}

The evaluation of criteria and decision-making perspective for the problem under study necessitates MCDM estimation models based on qualitative value judgments alongside quantitative data. Therefore, a combined LCA-LCC approach was used at an environmental and techno-economic level to quantify the quantitative criteria of our model. Furthermore, experts' judgment is used to evaluate qualitative criteria.

Primary data were collected through interviews with organizations and internal sources from institutions in Morocco, such as the Ministry of Mines, Energy, Water, and the Environment, the National Agency Of Waste Management, and Deutsche Gesellschaft für Internationale Zusammenarbeit (GIZ). Direct contact was established with 27 local and international companies and organizations in Morocco. Moreover, secondary data were collected from the Ecoinvent v3.6 database.

\section{Life-cycle environmental assessment}

The impact assessment was evaluated using the IMPACT World + due to its compatibility with all impact categories and evaluation prowess. The results of the evaluation of quantitative environment-safety-related criteria CES1, CES2, CES3, and CES5 (excluding employees risk exposure (CES4), which is qualitative) are shown in Fig. 4 (details are provided in Appendix II (Table 6)).

Regarding the infectious SW treatment alternatives, CHD + INC (SW3) has the best energy consumption benefit, followed by INC (SW1). The most "energivorous" choices are MCD + INC (SW5) followed by STD + INC (SW4). Moreover, STD + INC (SW4), MCD + INC (SW5), and CHD + INC (SW3) show the most disinfection efficiency. In terms of toxic gas release, INC (SW1) and CHD + INC (SW3) present the most advantage. However, RP (SW2) cannot offer the same benefit, and gas washing and monitoring should be considered. Finally, INC (SW1) is advantageous in terms of aquatic ecotoxicity. However, STD + INC (SW4) generates toxic WW, which needs to be treated.

Regarding the infectious WW treatment alternatives, energy consumption is not an issue in all alternatives. UF (WW4) is the best alternative as it relies on physical filtration. However, UF (WW4) is not advantageous in terms of disinfection efficiency and aquatic ecotoxicity. Other options, such as CHL + UVI (WW1) or even UF + UVI (WW3) are more efficient. Besides, UF (WW4) is more beneficial in terms of toxic gas release.

\section{LCC assessment}

In this study, LCC method was employed to evaluate the techno-economic criteria of different alternatives. Costrelated data of the various alternatives were identified based on the data gathered from organizations, companies, and treatment facilities consulted in Morocco. Data have been collected for different years from different organizations having comparable production capacity. Accordingly, the LCC of an infectious SW and WW treatment consists of the operation costs (i.e., initial investment, auxiliary materials, labor, maintenance) and external costs (including an external market cost for eco-remediation, atmospheric and aerosol releases, and human health protection). The financial profit was computed using total production units and the unit price of produced products (raw materials, energy, etc.). Figure 5 illustrates the quantification of the economic, technological, and social criteria (CEC1, CEC2, CEC3, and CSP1), whereas Appendix III (Table 7) detail the technoeconomic parameters. The INC (SW1) and CHD + INC (SW3) were ranked the best treatment alternatives on the economic performance with the minimum costs (external 
and internal), providing maximum profit and job creation. As for infectious WW treatment alternatives, UF (WW4) is economically the best alternative, although the low job creation due to the simplicity of processes compared to the other methods.

\section{Experts interviews}

The LCA-LCC inputs cannot be enough due to the scarcity of evidential data in infectious WM in Africa, especially when dealing with qualitative criteria. Therefore, we have used expert judgment to strengthen and complement our analysis. A total of 12 experts have been chosen from healthcare institutions, WM companies, NGOs, and governmental institutions in many African countries to reflect the assessment of different sides. The profiles of the expert's panel are provided in Appendix IV (Table 7).

\section{Evaluation of the Alternatives}

\section{Calculation of criteria weights using IVP-AHP}

Using a comparison survey, the experts were requested to employ the linguistic scale (Appendix I (Table 5a)) to evaluate the criteria. The IVF pairwise comparison matrix between all criteria has been constructed by using Eq. (1). The consistency ratio for each evaluation matrix for the criteria has been systematically computed based on Eqs. (2)-(4). After obtaining a CR $<0.1$ for all main criteria, the aggregated IVF evaluation matrix for the criteria weights is calculated. The IVF geometric means of the criteria have been calculated using Eq. (5). Hence, the IVF weights are obtained using Eq. (6). Moreover, the weights of 17 subcriteria are ranked based on the defuzzified global weights. The weights of the top three factors are identified according to experts' evaluation: disinfection efficiency (CES2), employees risk exposure (CES4), treatment capacity (CEC1). Table 3 depicts the overall findings.

\section{Prioritizations of infectious SW and WW treatment alternatives using IVP-VIKOR}

After calculating the global IV weights of the criteria, the evaluation of the infectious SW and WW treatment alternatives with respect to each criterion can be obtained. The experts have been consulted again to evaluate the importance of the alternatives with respect to the criteria using the linguistic scale (Appendix I (Table 5b)). Similarly, the IVF evaluation matrix and IVF decision matrix were determined using Eqs. (7) and (8), respectively. Thereafter, the positive $\left(P^{f^{*}}\right)$, negative $\left(N^{f-}\right)$, and weighted $\left(P^{v^{*}}\right)$ of IVF ideal solutions for upper and lower reference points are determined by using formulations in Step 3. The final rankings

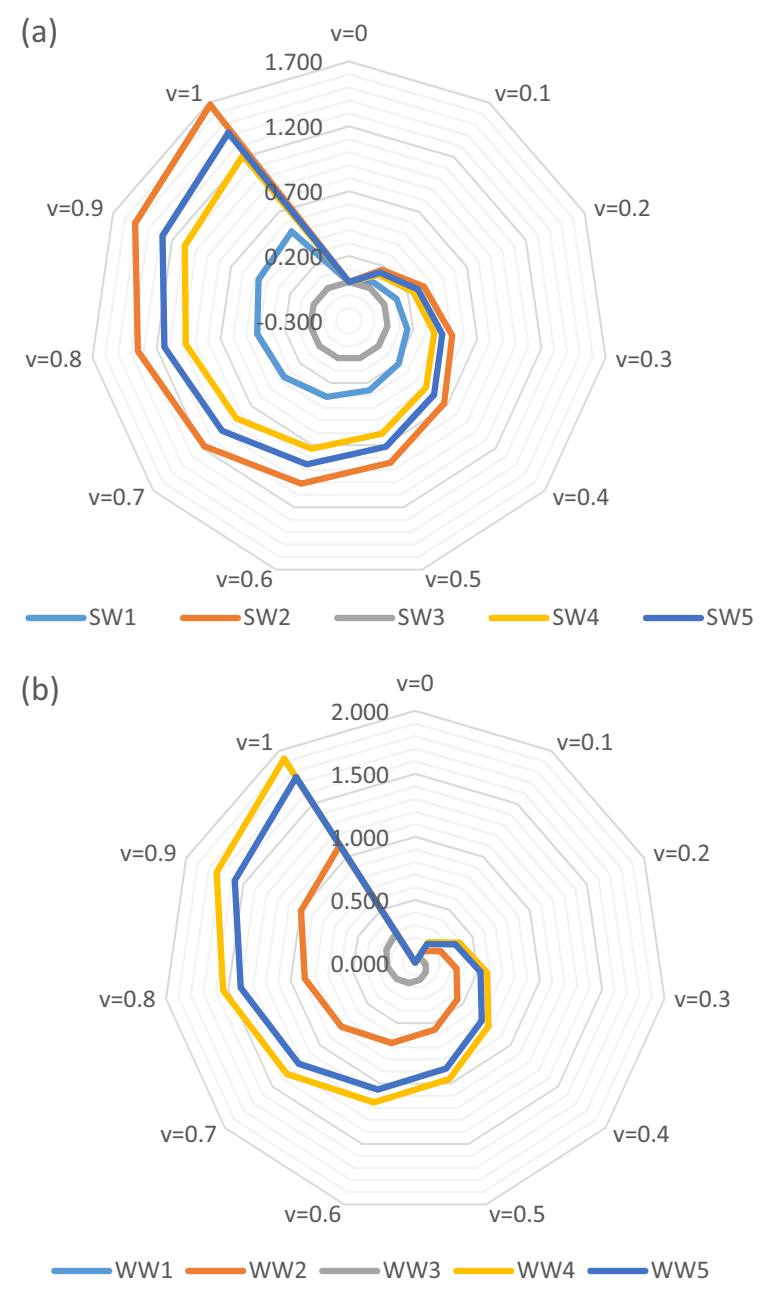

Fig. $6 Q_{i}$ values of a infectious $\mathrm{SW}$ and $\mathbf{b}$ infectious WW treatment alternatives for different maximum group utilities

are based on averages, and the worst group scores are determined using Eq. (16). The maximum group utility $(v)$ is set as 0.5 . Final rankings of infectious $\mathrm{SW}$ and WW treatment alternatives alongside related regret and average scores are illustrated in Table 4.

Regarding infectious SW treatment alternatives, acceptable advantage, the cond. 1 in Step 5 is satisfied among line SW3 $\left(Q_{3}=0.102\right)$ and SW1 $\left(Q_{1}=0.498\right)$. Hence, SW3 is selected as the best appropriate alternative. The infectious SW treatments can be sorted as SW3, SW1, SW4, SW5, and SW2 from the best to the worst alternative, based on the experts' decision.

\section{Sensitivity Analysis}

Sensitivity analysis was performed to analyze the impact of factors using VIKOR under the IVF environment on selecting SW and WW treatment alternatives during the COVID-19 pandemic. The maximum group utility $(v)$ was used to investigate the ranking of alternatives. 
Fig. 7 Proposed infectious municipal waste management during COVID-19 pandemic

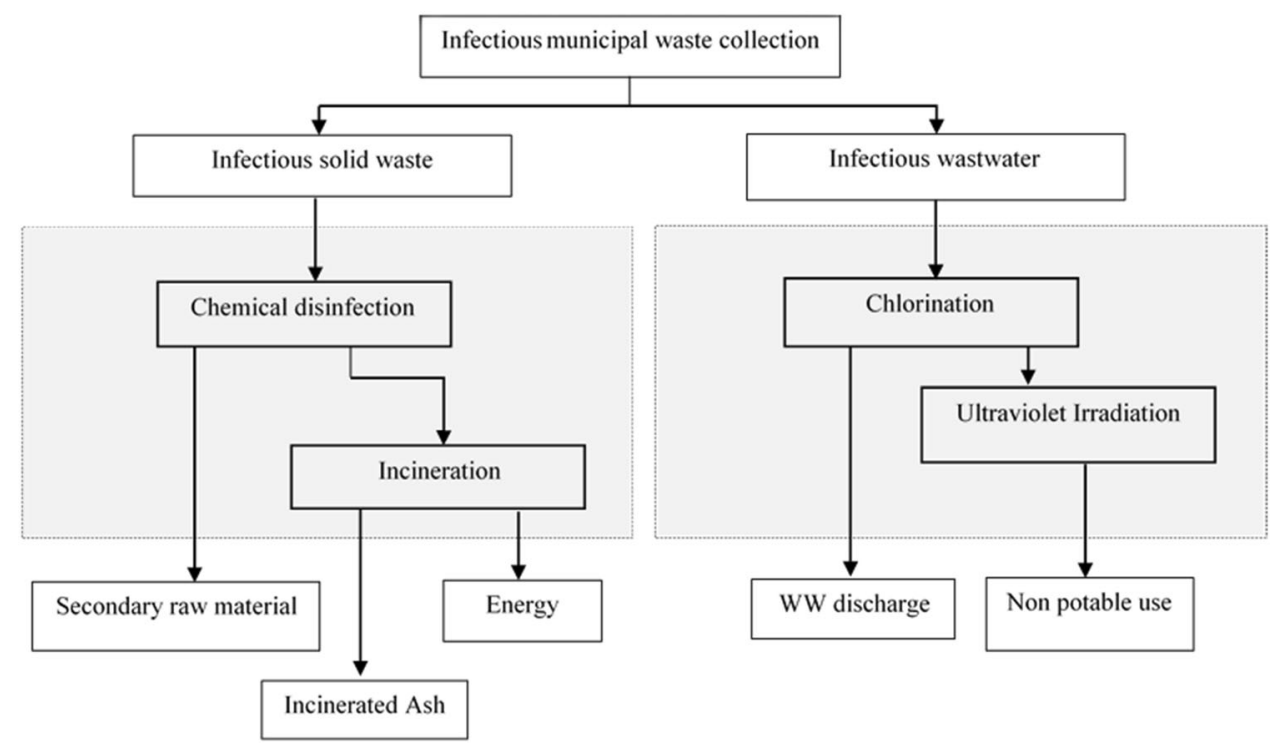

The maximum group utility value $(v)$ was set between 0.00 and 1.00 with an increment of 0.1 . The results of the sensitivity analysis are presented in Fig. 6 .

The sensitivity analysis shows that the ranking of alternatives remains unaffected under other cases confirming that the results of the ranking order are consistent. The sensitivity analysis establishes that the proposed approach yields good results and presents suitable outcomes for decision-makers.

\section{Discussion and Implications}

During the COVID-19 pandemic, infectious municipal SW and WW treatment is a critical issue worldwide to tackle the exponential increase of infectious waste generation during this period. This is even true for African developing and underdeveloped countries where the municipal WM is generally more economic-oriented and practiced in an unsustainable way (Idowu et al. 2019; Kabera et al. 2019). Recently, many government task forces have been formed in African countries to develop guidelines and operating procedures for managing infectious waste from COVID-19 in risk zones. In our study, we considered Morocco as a case study for developing an integrated MCDM methodology to select the most effective SW and WW treatment technology. Accordingly, Fig. 7 presents the integrated infectious municipal WM system suggested in this research.

Based on the ultimate prioritization of the infectious SW treatment alternatives, it could be noted that a combined approach, including CHD and INC, is the most suitable to the African context. Notably, INC of waste in most African countries is not widely considered before COVID-19 due to the technical and economic constraints and short-term vision
(Scarlat et al. 2015). However, coupled with CHD, infectious waste INC was explored as providing the maximum tradeoff at environment-safety, economics, technology, and socialpolitics levels on the medium to long term. Practitioners and policymakers adopting this alternative should start with an experienced, separated, and specialized waste collection for CHD. Moreover, a shredding step is highly required before CHD to enhance disinfection efficacity. Finally, rigorous monitoring of the collection phase is a prerequisite to limit the propagation of the SARS-CoV-2. Many organizations such as European Centre for Disease Prevention and Control (ECDC) (2020) and WHO (2020a, b) recognize the necessity of specific measures regarding the collection of household waste from infected areas to enhance the efficiency of the whole municipal WM in containing the SARS-CoV-2 spread.

Furthermore, an integrated CHL-UV irradiation approach was found to be the most suitable alternative for disinfecting and enhancing the reuse of WW. This finding is consistent with prior studies on SARS-CoV-1, which is similar to SARS-CoV-2. For instance, Chen et al. (2006) and Wang et al. (2005) reported that UV irradiation and CHL were the most effective in SARS-CoV-1 inactivation despite the inefficiency of ozone disinfection. Hence, we propose that chlorine disinfection $(50 \mathrm{mg} / \mathrm{l}$ during more than $1.5 \mathrm{~h}$ ) is adopted in this scheme (Lazarova et al. 1999). UV irradiation and heating should be incorporated due to lesser residues and perfect disinfection (Wang et al. 2020a, b; Lazarova et al. 1999).

\section{Conclusion}

During the COVID-19 pandemic, municipal WM is one of the vital utility services supporting industrial activity and 
society. The implementation of a suitable WM system for infectious SW and WW treatment in developing and underdeveloped countries, especially in Africa, is a challenging task requiring reliable and reasonable decisionmaking. The complexity of the problem lies in its dependency on numerous critical factors such as the environmental requirements, strategies in ecological management, statutes of the country, energy policy, technological and economic capabilities and feasibility, and education of citizens (Wang et al. 2020a, b; Idowu et al. 2019). To help decision-makers in the African context ascertain the current challenges of municipal WM and devise a suitable infectious waste treatment plan, a combined AHP and VIKOR method under the IVF environment is proposed to evaluate and prioritize the infectious SW and WW alternatives from an LCC-LCA perspective. Five alternatives (i.e., RP, CHD, INC, STD, and MCD) for infectious SW treatment were considered in this study. Similarly, five alternatives (i.e., CHL, UV irradiation, UF, and OZO) for infectious WW treatment were evaluated for WW disinfection technologies. An evaluation criteria system for the alternatives is constructed, including 17 criteria in four dimensions (environment-safety, economics, technology, and social politics).

Furthermore, data collected from professional contacts with 27 companies and institutions in Morocco and the consultation of national and international databases were used to conduct an LCA-LCC analysis. The results of the LCA-LCC are supplemented by judgments from a panel of 12 experts that supported to prioritize the alternatives for both infectious SW and WW treatment during the COVID19 pandemic. Accordingly, the proposed system for the management of contagious municipal waste in this study considers integrated strategies, including INC with CHD for infectious SW treatment and CHL with UV irradiation for infectious WW treatment.

The findings of the current study could provide useful and valuable insights for practitioners and policymakers in drafting a municipal WM system during the specific context of the COVID-19 pandemic. The suggested approach in this study can effectively integrate the environmental, safety-related, political, and social outcomes in selecting the most optimal solution for infectious WM among multiple alternatives rather than considering only techno-economic parameters.

This study can be considered as a starting point for approaching a significant and weakly addressed issue in the context of COVID-19. Therefore, the greatest need is to conduct empirical research on WM issues of developing and underdeveloped countries. One limitation of the proposed integrated MCDM model is that it continues to depend partially on expert opinion as the weights attributed to each criterion play a vital role in the final result. To tackle this problem, future studies must use mathematical optimization procedures such as linear programming, nonlinear programming, integer programming, etc., and perform a sensitivity analysis to assess the robustness of the results. Another limitation is the behavior of SARS-CoV-2. There is a lack of clarity on the products and processes required to manage the pandemic and the effect these products generate on coming in contact with the persons. Therefore, further studies are encouraged to compare findings in different countries' contexts, including changes in government guidance, technological development, and other factors. Moreover, more in-depth engineering analysis is needed to ensure that the proposed alternatives can deal with the dynamic and changing nature of the SARS-CoV-2.

\section{Compliance with Ethical Standards}

Conflict of Interest The authors declare that they have no conflict of interest.

Publisher's note Springer Nature remains neutral with regard to jurisdictional claims in published maps and institutional affiliations.

\section{Appendix I}

Table 5 Linguistic variables for (a) criterion importance used for IVFAHP comparison, and (b) performance of alternatives used for IVFVIKOR comparison

(a)

\begin{tabular}{ll}
\hline Level of importance & Triangular IVF number \\
\hline Equal importance & $(1,1) ; 1 ;(1,1)$ \\
Moderate importance & $(1,2) ; 3 ;(4,5)$ \\
Strong importance & $(3,4) ; 5 ;(6,7)$ \\
Very strong importance & $(5,6) ; 7 ;(8,9)$ \\
Extreme importance & $(7,8) ; 9 ;(9,9)$
\end{tabular}

(b)

\begin{tabular}{ll} 
Level of performance & Triangular IVF number \\
\hline Very poor & $(0.0) ; 0 ;(1,1.5)$ \\
Poor & $(0.0 .5) ; 1 ;(2.5,3.5)$ \\
Moderately poor & $(0.1 .5) ; 3 ;(4.5,5.5)$ \\
Fair & $(2.5,3.5) ; 5 ;(6.5,7.5)$ \\
Moderately good & $(4.5,5.5) ; 7 ;(8,9.5)$ \\
Good & $(5.5,7.5) ; 9 ;(9.5,10)$ \\
Very good & $(8.5,9.5) ; 10 ;(10.10)$ \\
\hline
\end{tabular}




\section{Appendix II}

Table 6 Data and calculation of the quantitative environment-safetyrelated criteria for (a) solid waste treatment and (b) wastewater treatment

\begin{tabular}{|c|c|c|c|c|c|}
\hline (a) & SW1 & SW2 & SW3 & SW4 & SW5 \\
\hline $\begin{array}{l}\text { Energy } \\
\text { consumption } \\
\text { (CES1) in } \mathrm{Kj}\end{array}$ & $3.24 \mathrm{E}+03$ & $5.12 \mathrm{E}+03$ & $1.13 \mathrm{E}+03$ & $5.32 \mathrm{E}+03$ & $5.82 \mathrm{E}+03$ \\
\hline $\begin{array}{l}\text { Disinfection } \\
\text { efficiency } \\
\text { (CES2) in \% }\end{array}$ & $85.48 \%$ & $81.12 \%$ & $91.11 \%$ & $92.42 \%$ & $92.15 \%$ \\
\hline $\begin{array}{l}\text { Toxic gas } \\
\text { mitigation (CES3) } \\
\text { in } \mathrm{kg} \mathrm{CO}_{2} \mathrm{Eq}\end{array}$ & $1.33 \mathrm{E}+03$ & $3.12 \mathrm{E}+03$ & $1.54 \mathrm{E}+03$ & $2.42 \mathrm{E}+03$ & $1.99 \mathrm{E}+03$ \\
\hline $\begin{array}{l}\text { Aquatic ecotoxicity } \\
\text { (CES5) in CTUe }\end{array}$ & $1.01 \mathrm{E}+04$ & $2.21 \mathrm{E}+04$ & $1.74 \mathrm{E}+04$ & $3.85 \mathrm{E}+04$ & $1.59 \mathrm{E}+04$ \\
\hline (b) & WW1 & WW2 & WW3 & WW4 & WW5 \\
\hline $\begin{array}{l}\text { Energy } \\
\text { consumption } \\
\text { (CES1) in } \mathrm{Kj}\end{array}$ & $6.18 \mathrm{E}+02$ & $6.22 \mathrm{E}+02$ & $6.35 \mathrm{E}+02$ & $1.13 \mathrm{E}+02$ & $8.58 \mathrm{E}+02$ \\
\hline $\begin{array}{l}\text { Disinfection } \\
\text { efficiency } \\
\text { (CES2) in \% }\end{array}$ & $95.33 \%$ & $90.19 \%$ & $92.69 \%$ & $75.13 \%$ & $90.48 \%$ \\
\hline $\begin{array}{l}\text { Toxic gas } \\
\text { mitigation }(\mathrm{CES} 3) \\
\text { in } \mathrm{kg} \mathrm{CO}_{2} \mathrm{Eq}\end{array}$ & $8.82 \mathrm{E}+03$ & $8.74 \mathrm{E}+03$ & $8.91 \mathrm{E}+03$ & $1.10 \mathrm{E}+02$ & $3.18 \mathrm{E}+03$ \\
\hline $\begin{array}{l}\text { Aquatic ecotoxicity } \\
\text { (CES5) in CTUe }\end{array}$ & $6.15 \mathrm{E}+03$ & $6.94 \mathrm{E}+05$ & $6.33 \mathrm{E}+05$ & $3.54 \mathrm{E}+04$ & $5.11 \mathrm{E}+03$ \\
\hline
\end{tabular}

\section{Appendix III}

Table 7 Data and calculation of quantitative techno-economic criteria for (a) solid waste treatment and (b) wastewater treatment

\begin{tabular}{lccccc}
\hline (a) & SW1 & SW2 & SW3 & SW4 & SW5 \\
\hline $\begin{array}{l}\text { External cost (CEC1) in } \\
\$ / k g\end{array}$ & 0.018 & 0.173 & 0.061 & 0.079 & 0.102 \\
$\begin{array}{l}\text { Operation cost (CEC2) in } \\
\$ / k g\end{array}$ & 0.542 & 0.959 & 0.998 & 1.201 & 1.041 \\
$\begin{array}{l}\text { Financial profit (CEC3) in } \\
\$ / \mathrm{kg}\end{array}$ & 0.356 & 0.037 & 0.295 & 0.119 & 0.097 \\
$\begin{array}{l}\text { Job creation (CSP1) in } \\
10^{6} \mathrm{MH} / \text { year }\end{array}$ & 59.42 & 61.83 & 60.51 & 66.48 & 76.18 \\
\hline (b) & WW1 & WW2 & WW3 & WW4 & WW5 \\
\hline $\begin{array}{l}\text { External cost (CEC1) in } \\
\$ / \mathrm{kg}\end{array}$ & 1.71 & 1.52 & 1.74 & 2.11 & 1.69 \\
$\begin{array}{l}\text { Operation cost (CEC2) in } \\
\$ / \mathrm{kg}\end{array}$ & 31.76 & 28.92 & 45.18 & 6.96 & 72.07 \\
$\begin{array}{l}\text { Financial profit (CEC3) in } \\
\$ / \mathrm{kg}\end{array}$ & 15.61 & 6.11 & 7.81 & 9.42 & 3.29 \\
$\begin{array}{l}\text { Job creation (CSP1) in } \\
10^{6} \mathrm{MH} / \text { year }\end{array}$ & 1.15 & 0.96 & 1.42 & 0.11 & 1.01 \\
\hline
\end{tabular}

\section{Appendix IV}

Table 7 Profile of experts

\begin{tabular}{|c|c|c|c|c|}
\hline Expert & Affiliation & Title & $\begin{array}{l}\text { Years of } \\
\text { experience }\end{array}$ & Country \\
\hline 1 & $\begin{array}{l}\text { Healthcare } \\
\text { institution }\end{array}$ & $\begin{array}{l}\text { Medical } \\
\text { specialist on } \\
\text { virology }\end{array}$ & 12 & Tunisia \\
\hline 2 & $\begin{array}{l}\text { Waste } \\
\text { management } \\
\text { company }\end{array}$ & $\begin{array}{l}\text { Operations } \\
\text { manager }\end{array}$ & 9 & Rwanda \\
\hline 3 & $\begin{array}{l}\text { Healthcare } \\
\text { institution }\end{array}$ & Labor doctor & 10 & Morocco \\
\hline 4 & Public institution & $\begin{array}{l}\text { Regional } \\
\text { director }\end{array}$ & 21 & Morocco \\
\hline 5 & Public institution & $\begin{array}{l}\text { Waste } \\
\text { management } \\
\text { portfolio }\end{array}$ & 15 & South Africa \\
\hline 6 & Consulting office & $\begin{array}{l}\text { Senior } \\
\text { consultant }\end{array}$ & 8 & Morocco \\
\hline 7 & $\begin{array}{l}\text { Waste } \\
\text { management } \\
\text { company }\end{array}$ & Design engineer & 5 & South Africa \\
\hline 8 & Consulting office & Project manager & 11 & Morocco \\
\hline 9 & $\begin{array}{l}\text { Regional } \\
\text { association }\end{array}$ & President & 10 & South Africa \\
\hline 10 & $\begin{array}{l}\text { Waste } \\
\text { management } \\
\text { company }\end{array}$ & $\begin{array}{l}\text { Executive } \\
\text { manager }\end{array}$ & 25 & Tunisia \\
\hline 11 & Local association & Vice-president & 16 & Morocco \\
\hline 12 & $\begin{array}{l}\text { Waste } \\
\text { management } \\
\text { company }\end{array}$ & Project manager & 15 & Cameroun \\
\hline
\end{tabular}

\section{References}

Ahmed W, et al. (2020) First confirmed detection of SARS-CoV-2 in untreated wastewater in Australia: A proof of concept for the wastewater surveillance of COVID-19 in the community. Sci Total Environ 728. www.elsevier.com/locate/scitotenv

Aung TS, Luan S, Xu Q (2019) Application of multi-criteria-decision approach for the analysis of medical waste management systems in Myanmar. J Clean Prod 222:733-745

Ayodele TR, Alao MA, Ogunjuyigbe ASO (2018) Recyclable resources from municipal solid waste: assessment of its energy, economic and environmental benefits in Nigeria. Resour, Conserv Recycl 134:165-173

Badi I, Ali S, Ali A, Eltayeb W (2019) Evaluation of solid waste treatment methods in Libya by using the analytic hierarchy process. Decis Mak 2(no. 2):19-35

Belhadi A, Touriki FE, El fezazi S (2019) Evaluation of critical success factors (CSFs) to lean implementation in SMEs using AHP: a case study. Int J Lean Six Sigma 10(no. 3):803-829 
Belhadi A, Touriki FE, El fezazi S (2018) Lean implementation in small and medium-sized enterprises in less developed countries: some empirical evidences from North Africa. J Small Bus Manag 56(no. sup1):132-153

Belhadi A, Touriki FE, El fezazi S (2017) Prioritizing the solutions of lean implementation in SMEs to overcome its barriers. J Manufg Technol Manag 28(no. 8):1115-1139

Belhadi A, Kamble SS, Zkik K, Cherrafi A, Touriki FE (2020) The integrated effect of big data analytics, lean six sigma and green manufacturing on the environmental performance of manufacturing companies: the case of North Africa. J Clean Prod 252

Chakraborty I, Maity P (2020) COVID-19 outbreak: migration, effects on society, global environment and prevention. Sci Total Environ 728

Chen C, Zhang X-J, Wang Y, Zhu L-X, Liu J (2006) "Waste water disinfection during SARS epidemic for microbiological and toxicological control”. Biomed Environ Sci 19(no. 3):173-178

Chen Z, Matthew EK, Liu Y, Wang Z (2018) The consequences of spatially differentiated water pollution regulation in China. J Environ Econ Manag 88:468-485

Coban A, Irem FE, Nur AC (2018) Municipal solid waste management via multi-criteria decision making methods: a case study in Istanbul, Turkey. J Clean Prod 180:159-167

Cobo S, Antonio D-R, Angel I (2018) From linear to circular integrated waste management systems: a review of methodological approaches. Resour, Conserv Recycl 135:279-295

Csutora R, Buckley JJ (2001) Fuzzy hierarchical analysis: the Lambda-Max method. Fuzzy Sets Syst 120(2):181-195

van Doremalen N et al. (2020) Aerosol and surface stability of SARSCoV-2 as compared with SARS-CoV-1. N Engl J Med 382 (16): $1564-1567$

ECDC (2020) Infection prevention and control in the household management of people with suspected or confirmed coronavirus disease (COVID-19). ECDC. https://www.ecdc.europa.eu/sites/ default/files/documents/Home-care-of-COVID-19-patients-202003-31.pdf. Accessed 15 May 2020

Ferreira S, Liu H, Brewer B (2018) The housing market impacts of wastewater injection induced seismicity risk. J Environ Econ Manag 92:251-269

Friedrich E, Trois C (2016) Current and future greenhouse gas (GHG) emissions from the management of municipal solid waste in the eThekwini Municipality-South Africa. J Clean Prod 112:4071-4083

Gherghel A, Teodosiu C, Notarnicola M, Gisi De S (2020) Sustainable design of large wastewater treatment plants considering multicriteria decision analysis and stakeholders' involvement. J Environ Manag 261

Gogoi A, Mazumder P, Tyagi VK, Chamindad GGT, An AK, Kumar. M (2018) Occurrence and fate of emerging contaminants in water environment: a review. Groundw Sustain Dev 6:169-180

Gupta P, Mehlawat MK, Grover N, Pedrycz W (2018) Multi-attribute group decision making based on extended TOPSIS method under interval-valued intuitionistic fuzzy environment. Appl Soft Comput 69:554-567

Guy JS, Breslin JJ, Breuhaus B, Vivrette S, Smith LG (2001) Characterization of a coronavirus Isolated from a diarrheic foal. J Clin Microbiol 38(12):4523-4526

Heidari MR, Heravi G, Esmaeeli AN (2020) Integrating life-cycle assessment and life-cycle cost analysis to select sustainable pavement: a probabilistic model using managerial flexibilities. J Clean Prod 254

Hong J, Zhan S, Yu Z, Hong J, Qi C (2018) Life-cycle environmental and economic assessment of medical waste treatment. J Clean Prod 174:65-73

Hu J, Chu W, Sui M, Xu B, Gao N, Ding S (2018) Comparison of drinking water treatment processes combinations for the minimization of subsequent disinfection byproducts formation during chlorination and chloramination. Chem Eng J $335: 352-361$

Idowu IA et al. (2019) An analyses of the status of landfill classification systems in developing countries: sub Saharan Africa landfill experiences. Waste Manag 87:761-771

Im D, Nakada N, Fukuma Y, Kato Y, Tanaka H (2018) Performance of combined ozonation, coagulation and ceramic membrane process for water reclamation: effects and mechanism of ozonation on virus coagulation. Sep Purif Technol 192:429-434

Istrat I-R, Iribarren D, Gálvez-Martos J-L, Dufour J (2020) Review of life-cycle environmental consequences of waste-to-energy solutions on the municipal solid waste management system. Resour, Conserv Recycl 157

Jack L (2006) Drainage design: factors contributing to Sars transmission. In: Proceedings of the Institution of Civil Engineers Municipal Engineer, ICE Publishing, Scotland, 159. pp. 43-48

JPC (2020) Joint prevention and control mechanism of the state Council. JPC. http://www.gov.cn/xinwen/gwylflkjz53/index.htm. Accessed 30 Apr 2020

Kabera T, Wilson DC, Nishimwe H (2019) Benchmarking performance of solid waste management and recycling systems in East Africa: comparing Kigali Rwanda with other major cities. Waste Manag Res 37(no. 1_suppl):58-72

Kharat MG, Murthy S, Kamble SJ, Raut RD, Kamble SS, Kharat MG (2019) Fuzzy multi-criteria decision analysis for environmentally conscious solid waste treatment and disposal technology selection. Technol Soc 57:20-29

Klemeš JJ, Fan YV, Tan RR, Jiang P (2020) Minimising the present and future plastic waste, energy and environmental footprints related to COVID-19. Renew Sust Energy Rev 127:109883

Kühn KP et al. (2003) Disinfection of surfaces by photocatalytic oxidation with titanium dioxide and UVA light. Chemosphere 53:71-77

Lazarova V, Savoye P, Janex ML, Blatchley III ER, Pommepuy M (1999) Advanced wastewater disinfection technologies: state of the art and perspectives. Water Sci Technol 40(no. 4-5):203-213

Li J, Xiao F, Zhang L, Amirkhanian SN (2019) Life cycle assessment and life cycle cost analysis of recycled solid waste materials in highway pavement: a review. J Clean Prod 233:1182-1206

Liu B, Tang J, Li Z, Yan Y, Chen J (2020) Optimal selection of sewage treatment technologies in town areas: a coupled multicriteria decision-making mode. Environ Manag, 66:709-721

Mallapaty S (2020) How sewage could reveal true scale of coronavirus outbreak. Nature 580:76-177

Munasinghe-Arachchige SP, Abeysiriwardana-Arachchige ISA, Delanka-Pedige HMK, Nirmalakhandan N (2020) Sewage treatment process refinement and intensification using multicriteria decision making approach: a case study. J Water Process Eng 37

Nabavi-Pelesaraei A, Bayat R, Hosseinzadeh-Bandbafha H, Afrasyabi H, Berrada A (2017) Prognostication of energy use and environmental impacts for recycle system of municipal solid waste management. J Clean Prod 154:602-613

Nabavi-Pelesaraei A, Bayat R, Hosseinzadeh-Bandbafha H, Afrasyabi H, Chau K-w (2017) Modeling of energy consumption and environmental life cycle assessment for incineration and landfill systems of municipal solid waste management - a case study in Tehran Metropolis of Iran. J Clean Prod 148:427-440

Nahman A, Godfrey L (2010) Economic instruments for solid waste management in South Africa: opportunities and constraints. Resour, Conserv Recycl 54(8):521-531

Narayanamoorthy S, Annapoorani V, Kang D, Ramya L (2019) Sustainable assessment for selecting the best alternative of reclaimed water use under hesitant fuzzy multi-criteria decision making. IEEE Access 7:137217-137231 
Nghiem LD, Morgan B, Donner E, Short MD (2020) The COVID-19 pandemic: considerations for the waste and wastewater services sector. Case Stud Chem Environ Eng

OECD/GIZ (2019) Access to water and sanitation in sub-Saharan Africa. OECD/GIZ. https://www.oecd.org/water/GIZ_2018_Access_Study_ Part\%20I_Synthesis_Report.pdf. Accessed 16 Sep 2020

Opricovic S (1998) Multicriteria optimization of civil engineering systems. Fac Civil Eng 2(1):5-21

Opricovic S, Tzeng G-H (2007) Extended VIKOR method in comparison with outranking methods. Eur J Oper Res 178(2):514-529

Phonphoton N, Pharino C (2019) Multi-criteria decision analysis to mitigate the impact of municipal solid waste management services during floods. Resour, Conserv Recycl 146:106-113

Ren J, Lützen M (2015) Fuzzy multi-criteria decision-making method for technology selection for emissions reduction from shipping under uncertainties. Transp Res Part D 40:43-60

Ren J, Toniolo S (2020) Life cycle sustainability prioritization of alternative technologies for food waste to energy: a multi-actor multi-criteria decision-making approach. In: Waste-to-energy. p 345-380

Saadat S, Chaudhery DR, Hussain M (2020) Environmental perspective of COVID-19. Sci Total Environ 728. www.elsevier.com/ locate/scitotenv

Saaty TL (1977) A scaling method for priorities in hierarchical structures. J Math Psychol 15(no. 3):234-281

Saaty TL (1980) The analytic hierarchy process: planning, priority setting. In: Resource allocation. McGraw-Hill, New York, NY

Sarkkinen M, Kujala K, Gehor S (2019) Decision support framework for solid waste management based on sustainability criteria: a case study of tailings pond cover systems. J Clean Prod 236

Scarlat N, Motola V, Dallemand JF, Monforti-Ferrario F, Mofor L (2015) Evaluation of energy potential of municipal solid waste from African urban areas. Renew Sustain Energy Rev 50:1269-1286

Stolze R, Kühling J-G (2009) Treatment of infectious waste: development and testing of an add-on set for used gravity displacement autoclaves. Waste Manag Res 27(4):343-353

Street R, Malema S, Mahlangeni N, Mathee A (2020) COVID-19 wastewater surveillance: an African perspective. Sci Total Environ

Tang W (2020) The medical waste related to COVID-2019 is cleaned up every day-the medical waste treatment market needs to be standardised. www.21jingji.com/2020/3-12/ xNMDEzODFfMTU0MjIxNQ.html. Accessed 30 Apr 2020

Tenenbaum L (2020) The amount of plastic waste is surging because of the coronavirus pandemic. https://www.forbes.com/sites/laura tenenbaum/2020/04/25/plastic-waste-during-the-time-of-covid19/\#121dcda7e484. Accessed 1 May 2020

World Bank (2020) Appraisal environmental and social review summary. World Bank. http://documents.worldbank.org/curated/en/ 921211585917393014/pdf/Appraisal-Environmental-and-SocialReview-Summary-ESRS-Lao-PDR-COVID-19-ResponseProject-P173817.pdf. Accessed 13 May 2020

Undri A, Frediani M, Rosi L, Frediani P (2014) Reverse polymerization of waste polystyrene through microwave assisted pyrolysis. J Anal Appl Pyrolysis 105:35-42

UNICEF (2020) COVID-19 emergency preparedness and response. UNICEF. https://www.unicef.org/media/66386/file/WASH-COVID- 19-infection-prevention-and-control-in-health-care-facilities-2020. pdf. Accessed 6 May 2020

Valente M, Bueno M (2019) The effects of pricing waste generation: a synthetic control approach. J Environ Econ Manag 96:274-285

Veronesi P, Leonelli C, Moscato U, Cappi A, Figurelli O (2005) Nonincineration microwave assisted sterilization of medical waste. $\mathrm{J}$ Microw Power Electromagn Energy 40(no. 4):211-218

Von Gunten U (2003) Ozonation of drinking water: part II. Disinfection and byproduct formation in presence of bromide, iodide or chlorine. Water Res 37(7):1469-1487

Voudrias EA (2016) Technology selection for infectious medical waste treatment using the analytic hierarchy process. J Air \& Waste Manag Assoc 66(7):663-672

Wang B, Song J, Ren J, Li K, Duan H, Wang X (2019) Selecting sustainable energy conversion technologies for agricultural residues: a fuzzy AHP-VIKOR based prioritization from life cycle perspective. Resour, Conserv Recycl 142:78-87

Wang J, et al. (2020a) Disinfection technology of hospital wastes and wastewater: suggestions for disinfection strategy during coronavirus Disease 2019 (COVID-19) pandemic in China. Environ Pollut 262

Wang P, Chen K, Zhu S, Wang P, Zhang H (2020b) Severe air pollution events not avoided by reduced anthropogenic activities during COVID-19 outbreak. Resour, Conserv Recycl 158

Wang X-W et al. (2005) Study on the resistance of severe acute respiratorysyndrome-associated coronavirus. J Virol Methods 126:171-177

Wang Z, Ren J, Goodsite ME, Xu G (2018) Waste-to-energy, municipal solid waste treatment, and best available technology: comprehensive evaluation by an interval-valued fuzzy multi-criteria decision making method. J Clean Prod 172:887-899

WHO (2020a) Coronavirus disease (COVID-19) situation report-114. WHO. https://www.who.int/docs/default-source/coronaviruse/situa tion-reports/20200513-covid-19-sitrep-114.pdf?sfvrsn=17ebbbe_ 4. Accessed 13 May 2020

WHO (2020b) Water, sanitation, hygiene, and waste management for the COVID-19 virus. WHO. https://apps.who.int/iris/bitstream/ha ndle/10665/331846/WHO-2019-nCoV-IPC_WASH-2020.3-eng. pdf. Accessed 1 May 2020

WHO/UNICEF (2017) Progress on drinking water, sanitation and hygiene: 2017 update and SDG baselines. UNICEF Publications. https://www. unicef.org/publications/files/Progress_on_Drinking_Water_Sanita tion_and_Hygiene_2017.pdf. Accessed 14 Sep 2020

Yao L, Xu Z, Lv C, Hashim M (2020) Incomplete interval type-2 fuzzy preference relations based on a multi-criteria group decision-making model for the evaluation of wastewater treatment technologies. Measurement 151

Yu DEC, Razon LF, Tan RR (2020) Can global pharmaceutical supply chains scale up sustainably for the COVID-19 crisis? Resour, Conserv Recycl 159

Zanghelini GM, Cherubini E, Soares SR (2018) How multi-criteria decision analysis (MCDA) is aiding life cycle assessment (LCA) in results interpretation. J Clean Prod 172:609-622

Zhang Z, et al. (2019) Pilot-scale evaluation of oxidant speciation, 1,4dioxane degradation and disinfection byproduct formation during UV/ hydrogen peroxide, UV/free chlorine and UV/chloramines advanced oxidation process treatment for potable reuse. Water Research 164 